\title{
Hacia una determinación de la realidad sacerdotal. El servicio al acercamiento salvífico de Dios a los hombres
}

\section{JON SOBRINO}

Centro de Reflexión Teológica San Salvador

\section{La problemática de la realidad sacerdotal y el modo leoológico de abordarla}

En la lglesia hay sacerdocio, común y ministerial, hay realizaciones de ese sacerdocio y hay una doctrina sobre él. Muchas cosas han cambiado después del Vaticano II y Medellin y esos cambios son juzgados diversamente como positivos o negativos. La misma práctica sacerdotal, honradamente discernida, esclarece descle dentro la bondad de esa novedad y también sus posibles peligros. Pero creemos que además se necesita un esclarecimiento teórico de la realidad sacerdotal pues persiste su problemática.

1.1. Si nos fijamos en lo ocurrido en América Latina después del Vaticano 11 y Medellin, de la mistna realidad surgen fuertes preguntas hacia el sacerdocio, sea cual fuere el modo como se resuelvan en la práctica. Por lo que loca al sacerdocio ministerial, no se pucde dudar de que el sacerdote se ve confrontado con fuertes cuestionamientos que le alañen en lo más profundo de su persona. En primer lugar, que signiliza ser sacerdole en un mundo de miseria e injusticia, de esperanza y movimiestos de liberación; cómo integrar su pacífica existencia sacerdoral anterior en un mundo convulsionado; como traducit creativanente las antiguas funciones sacerdotales de modo que sean relevantes y creíbles en esta nueva realidad. En segundo lugar, qué signi mente, dirigir, ser responsable de una comunidad cuando los laicos -animados en principio por la lglesia- loman conciencia de su hugar y misión dentro de la lglesia, y - lo que es más novedoso- cuando los mismos sacerdotes comprueban repetidamente que no sólo dan sino que reciben, no sólo enseñan sino que son enseñados, no sólo aniınan sino que son animados por sus mismas comunidades, y ello a los más profundos niveles de la $\int_{c}$, la esperanza y el amor cristianos. El ministerio de dirección y liderazgo iniraeclesiales, aunque mantenga lormalmente su necesidad, cambia muy suslancialmente en su conlenido. En tercer lugar, qué consecuencias liene participar en 
lo sacerdolal de la lglesia desde la jerarquia - pues los sacerdores ministeriales son comprendidos como lales más desde su relación con el episcopado que desde su relación con cl sacerdocio de los fieles-, lo cual les otorga sin duda ventajas para su elicacia apostólica. pero les puede cuestionar, incluso en conciencia, cuando la jerarquía no es vista como salvifica, sino como opresora, así como sienten el gozo de participar en el poder jerárquico cuando éste está volcado ell lavor de los pobres. Por último, qué significa espiritualidad sacerdotal, la cual -adeinás de las exigencias tradicionales que persisten- tiene que aumar hoy elementos tan disparejos como lo jerárquico y lo popular de la base, lo religioso y lo sccular. el lrabajo personal y el trabajo integrado en roda una pastoral de conjunto. Junto a esta problemática existen muchos otros problemas prácticos alrededor de lo sacerdotal. Entre éstos están, cómo se determinan y jerarcuizan las funciones saccriotales, cuáles son 'estrictamente' sacerclorales y cuáles son convergentes y/o acompañantes, cuál es la relación del sacerdote con cl mundo de la política y de las tevoluciones, qué le está permitido y qué rıo, cómo llevar a cabo un diálogo con las comunidades y con la jerarquia, cuándo se llega a la siluación de una legitima denuncia profética dentro de la Iglesia, cuya institucionalidad ellos también representan. En otro orden de cosas, está la problemática de la formación de los futuros sacerdotes en los seminarios - gravisimo problema en el presente-, quién la determina, qué participación lienen los sacerdoles y los fieles en su configuración y evaluación etc. Todos estos problemas pueden ser zanjados administrativamente, pero sólo esa solución no garantiza que se los haya resuelıo bien.

Por lo que toca al sacerdocio común hay que reconocer que ha aumentado la participación de los laicos clentro de la Iglesia; pero, por otra parte, no ha quedado claro que es lo suyo 'sacerdotal'. Se les ha dado más responsabilidad pastoral y mayor participación en la liturgia; pero no se ha avanzado mucho en reconocerles también como el lugar eclesial de la fe (clr. $L G$ I2) y a quienes la Iglesia jerárquica debe atender también al elaborar su doctrina. Al nivel de la práclica de la caridad, la Iglesia los anima -en parte para que no lo hagan los sacerdotes ministeriales - a que se introduzcan y trabajen en el mundo, también en el resbalidizo mundo de la política, los partidos y las organizaciones populares; pero no in [recuentemente se encuentran entonces abandonados por la jerarquía y los sacerdotes - pocos obispos han exigido consecuentemente, como Mons. Romero, la pastoral de acompañamiento en esos difíciles campos- de modo que se preguntan por qué se les animó a ello y si es verdad que ese mundo de la historia y de la política es campo de su sacerdocio.

Junto a estos problemas más inmediatos subsisten otros más teóricos, aun después del Vaticano II. Subsiste la tensión teórica entre la potestad sagrada excluyente que se otorga por el sacramento del orden -lo cual pareceria remitir lo sacerdotal directamente a la esfera del culto-y la primacía práctica que se le da al ministerio de la palabra ( $P O 4)$. Sigue sin esclarecerse teóricamente por qué unas actividades seculares puedan ser exigidas 0 , al menos, permitidas a los sacerdotes y otras no. Sigue sin esclarecerse lo verdaderamente común al sacerdocio 'ministerial' y 'común,' de modo que las diferencias se comprendan desde lo que abarca a ambos. Sigue sin esclarecerse la relación entre sacerdocio 
y vida religiosa, en el caso del religioso ordenado, y persiste la L゙nsión léricia entre lo que de 'profético' le compere a la vida relieviosa por su escircia y lo cute de 'ministerial' le compele al sacerdocio.

1.2. Todos estos problemas, y muchos otros, pueden ser smumerados al tralar de lo sacerdotal. Su tralamiento debe ser sin duda teológico, pero también espiritual, pastoral e histórico (sociológico. cultural. politico y econcimico).

L.o que queremos recalcar, sin embargo, es quic al menciomar csta pléyade

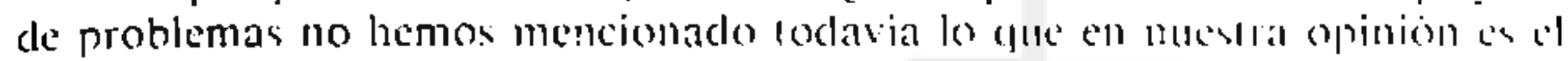
problema fundamental. Y éste no es otro yac responcles al csla sencilla prepuluta: qué es lo sacerdolal. Responder a las clemás preguntas, sil origen, sus funciones, su diferenciación clc., es importante y algo ayudan: pero no contestan todavia a la pregunta fundamental. Y' si no se conleva a esla pregumla no solo persistirán las otras, sino que no se habrá proporcionado el criterio fundamenlal para discernir en las complejas respuestas. Esto es lo que intentamos hacer cn este trabajo con la modestia indicada en el titulo: intemlar deicrminar lá realidad sacerdotal. Pero para ello nos parece importante esclatecer dos problemas previos: la finalidad de lo sacerdolal y el modo teológico de abordar lo sacerdolal.

Aunque sea todavia de forma introductoria es importante recordat cuál es la finalidad de lo sacerdotal. a qué realidad humana c historlica hat respondido lo sacerdolal y lo ha hecho necesario. Esa linalidad no es otra cue la salvación, aquello que han buscado los hombres desde siempre. En este momento no es importante analizar si las religiones históricas en läs que ha surgido lo sacerdolal han respondido mal o bien a ese problema; pero si es imporlante recordar que lo sacerdotal ha expresado la realidad de una humanidad necesitada de sal. vación y con la esperanza de conseguir salvación. De esta lorma lo sacerciolal ha remitido siempre a una problenática cotalizanle y no reșional; y ha respondido a la problemática más importante de la humaniclad: la salvación.

La pregunta por la salvación, formulada explicita o implicilamente, religiosa o secularmente, siempre ha cstado ahi. Expresadal religiosamente, siempre se ha relacionado con Dios. En liempo de Iesis los pohres esperaban el advenimiento del reino de Dios, Pablo habla de una humanidad impaciemte, que abriga la esperanza de verse liberada de la esclaviud, cle un luluro donde se revele lo que es ser hijos de Dios. Muchos siglos mis tarde, cul los albores de la modernidad. Lutero se preguntaba como encontrar a un Dios benćvolo. Las necesidades - o la conciencia de ellas - han podido cambiar a lo largo de la historia, pero el remitirse a Dios ha estado siempre en el maleo de la salsación. Y según eso ha ido cambiando la noción de londo de lo sacerdolal. como se ve en Ios ejemplos aducidos (lcl N.T. y de I.ulero.!

En la actualidad del tercer mundo poca duda cabe de que hay pueblos enteros que esperan la salvación. En Amćrica Lalina esa necesiclad de salvación ha sido expresada de forma histórica y religiosa, apuntando a la necesidad más hiriente que necesita salvación y al Dios que la suscila. Valgan por muchas una conocida cila de Medellín: "Eslamos en el umbral de una Época histórica de 
nuestro continente, llena de un anhelo de emancipación total, de liberación de loda servidumbre, de maduración personal y cle integración colectiva," todo lo cual es interpretado religiosanente como "un cvidente signo del Espíritu que conduce la historia de los hombres y de los pueblos hacia su vocación" (Introducción 4).

Con esı queremos decir que la problemática sacerdoıal está muy viva en América Latina, se la denomine o no con ese nombre, y que lo sacerdolal debe ser comprendido desde esa problemática globalizante. Con ello no se ha dicho todavía casi nada sobre la salvación y como clebe de ser entendida, ni nada sobre cl acceso a la salvación. Pero se ha intentado retrotraer el sacerdocio a su ámbito coralizante. para comprenderlo desde ahi y no desde sus realidades y problemálicas regionales. Aunquc sea de pasada, digamos que los obispos $-y$ las comunidades - que han comado más ell scrio la necesidad global de salvación, como Don Helder Camara, Don Pedro Casádaliga, Mons. Romero, por poner sólo algunos ejemplos, han sido también los más sacerdolales; han revalorizado el sacerdocio común y el ministerial.2

En la conciencia oficial de la lglesia, aunque la teologia haya ido más adelante, ${ }^{3}$ lo sacerdotal sigue siendo tratado como algo regional más que totalizante; y la salvación que media lo sacerdolal sigue sienclo comprendida como lo ya sabido más que como lo que debe ser sicmpre aprendido. El Valicano II, lan renovador en otros puntos, no lo fue especialmente en éste y aclararse por qué puede ser útil para la determinación de lo sacerdotal.

Es cierto que el concilio fundamenta todo sacerdocio en el de Cristo ( $P O$ 2), y que - Inás novedosamente- revalorizó el sacerdocio de todos los bautizados ( $L G 10 ; P O 2$ ) y el ministerio de la palabra sin reducir lo sacerdolal ministerial a lo cúltico (PO 4). Pero en el análisis concreto de lo sacerdolal, éste es tratado más regionalmente dentro de lo que el sacerdote ordenado es en la Iglesia que de forma totalizantét $Y$, paradójicamence, la salvación globalizante está mejor expuesta en la Lumen Gentium y Gaudium et Spes que en la Presbiterortm Ordinis, de modo que cuando se habla de la total salvación de Dios no se menciona de modo iniportante io saccrclolal y cuando se menciona este no se menciona de forma importante lal salvalcion lolal de Dios. Varias pueden ser las razones por las que el Concilio abordó la realiclad sacerdotal de esta inanera ${ }^{5}$, pero aqui sólo queremos conviatar su modo teológico Je proceder en este punto, tan distimto al modo de proceder en olros temas importantes. Si se nos permile un breve excurso, podemos recordar que la Iglesia ya poseia importanles conceptor sistemálicos sobre la misma lglesia y sobre la revelación, y sin embargo prolundiró en cllor y lon renovó por el método télogico de fondo del que hizo uso: comprender ambas realidades desde Cristo y desde el Dios que se hizo presente concrelamenle en Jesiss. Si la misma Iglesia es considerada como sacramento de salvación es porque Cristo es sacramento ( $L G$ 1); si la Iglesia tiene como misión anunciar e instaurar el reino de Dios en lodos los nueblos, es porque Jesús lo anunció e insıauró ( $L G S$ ); si la Iglesia concibe novedosamente $-y$, en la práctica, contrariamente - su relación con el mundo como relación de servicio, es porque Cristo vino "para servir y no 
para ser servido" (GS 3); si aparece ya una incipienle opción eclesial por los pobres y una llamada a la pobreza $(G S \mathrm{I} ; L G 8)$, es porque Cristo "fue cuviado por el Padre a evangelizar a los pobres y levantar a los oprimidos (1.0 4,18), para buscar y salvar lo que estaba perdido (LC 19,19)" (LC 8). Y lo mismo puede decirse de la comprensión sistemática de revelación. Si se supera una concepción más bien doctrinaria de la revelación a través de enunciados verdaderos en favor de una revelación de Dios en si mismo que sc comunica al hombre a través de hechos y palabras, es porque Cristo "habla palabras de Dios $(\mathrm{Jn} 3,34)$ y lleva a cabo la obra de salvación" (DV 4$)$.

Y el mismo proceder usó Pablo Vl en la Eramgénir Nimiamdl al hablat de la evangelización, apelando consecuentemente a Cristo. Si afirma de la crangelización que en ella consiste la identidad más profunda de la Iglesia (1).14), si avanza en la definicion de evangelización como "llcvar la Buena Nucva a rodos los ambientes de la humanidad $y$, con su influjo, Iransformal desde dentro, renovar a la misma humanidad" (n.18), si añade a los Iradicionales modos de evangelización - anuncio y testimonio - el modo novedoso de la li. beración (nn. 29-31), es porque previamente a la evangelización de la lglesia ha analizado la evangelización de Cristo y, por cierto, la evangelización de Jesús de Nazaret (nn. 6-12), "el primer evangelizador"' (n.7). Si Medellín y Puebla hablan de la solidaridad de la Iglesia con los pobres y de su opción prefcrencial por ellos, es porque antes han analizado la obra de Jesús y hall relacionaclo a los pobres con el mismo Dios (cfr. Puebla nn. 1141s).

Este breve recordatorio muestra que es posible la reelaboración de conceptos sistemáticos de realidades sumamente importantes para la lglesia y que la Iglesia lo ha llevado a cabo; que esa reelaboración recoge lo mcior de la lradición eclesial, pero la enriquece insospechadamente; que esos nuevos conceplos sistemáticos son más ricos, tienen mayor densidad, generan más crealividad intraeclesial, poseen más relevancia histórica y otorgan mayor crédibilidad a la Iglesia. Pero hay que recordar que esa novedad enriquecedora ha provenido de la confrontación humilde y honrada de la Iglesia con Cristo y con Dios; es decir, de un modo de proceder teológico no meramente inlraeclesial o a partir sólo de la eclesiología, sino de la cristo-logía y la teo-logia: de un modo de proceder que toma en serio los signos de los tiempos y está guiado por cl interés de salvar al hombre.

En el esclarecimiento de la realidad sacerdotal crecmos que no se ha seguido consecuentemente ese modo de proceder lcológico. Lis cierto que se aliil ma que el único sacerdocio verdadero es el de Crisıo; pero en el análisis concreto del sacerdocio aquél queda como un presupuesto teórico que no incicle grandemente en éste. Dicho con toda sencillez: ise puede afirmar que la lglesia. al determinar la existencia sacerdotal, la verificación de si ha habiclo o no realidad sacerdotal, se fija consecuentemente en el sumo sacerdote de la Carta a los Hebreos? ¿No da más bien la sensación de que ya sabe suficientementc lo quc son y deben hacer los sacerdoles, cómo ha de ser su exislencia, qué virludes deben fomentar etc., con anterioridad lógica a la carla?

Y algo semejante debe decirse de la determinación sistemática de la reali- 
dad sacerdoral. Es cierto que el concilio of rece en dos ocasiones una definición tolalizante de esa realidad. Al hablar de los presbíteros dice que su misión consiste en "procurar la gloria de Dios Padre en Cristo," la cual consiste en que "los hombres reciban consciente, libremente y con gratitud la obra divina realizada en Cristo y la manifiesten en toda su vida" (PO 2); y al hablar del sacerdocio comun de los bautizados dice que "por medio de toda obra buena del hombre cristiano ofrezcan sacrificios espirituales y anuncien el poder de Aquel que los llamó de las (inieblas a su admirable luz." (L.G 10;PO 2). Pero estas delerminaciones permanecen genéricas, no analizan a fondo ni en relación con lon signos de los tiempos lo que sea "la gloria de Dios" o "los sacrificios espirituales." De nuevo, no hay suficiente análisis de la realidad de Dios cuando se habla de lo sacerdotal, de modo que lo sacerdotal pueda remitirse concretamente a Dios.

1.3. Lo que intentamos a continuación es determinar la realidad sacerdotal desde sus raices más profundas, desde la teo-logía y la cristo-logia. Con ello no se resolvcrán lodos los problcınas iniraeclesiales cuncretos mencionados y varios de ellos no pueden resolverse por pura argumentación teológica, pues dependen de decisiones históricas que la Iglesia ha ido haciendo legitimamente, aunque algunas de ellas pudieran ser también revisables. Pero si se esclarecc la realidad sacerdotal entonces mejor se esclarecerán los problemas concretos y en cualquier caso se presentará aquel minimo -o máximoque no debe fallar en ninguna conlïguración histórica del ejercicio sacerdotal, ministerial y común.

A continuación tralaremos de elaborar un concepto teórico de la realidad sacerdolai, reniendo en cuenta los origenes de la fe -la realidad de Dios y de Cristo-y los actuales signos de los tiempos. Aunque teórico, por lo tanto, este trabajo está guiado por la realidad sacerdotal tal como lo vemos en América Latina, de lo cual diremos brevemente una palabra al final. ${ }^{6}$

\section{La dimensión teo-lógica de lo sacerdotal}

Comenzamos con la dimensión teo-lógica de lo sacerdotal, lo cual significa responder a esta pregunta: a qué realidad concrela dcl Dios en el que cree la Iglesia corresponde lo sacerdotal. La respuesta directa a esta pregunta es estrictamente imposible sin tener en cuenta a Cristo. Pero comenzamos con la dimensión teo-lógica -sobreentendiéndose que en el análisis nos dejamos guiar por la aparición de Dios en Cristo- para presentar lo sacerdotal de la forma más radical y última posible en el inarco de la teo-logia y la antropologia; y porque creemos también que la realidad de Cristo, incluido su sacerdocio, debe ser comprendida relacionalmenle. Además, el análisis que suele hacerse del sacerdocio de Cristo en la carla a los Hebreos ha lendido, con razón, a mostrar la historicidad de su sacerdocio y su sacrificio en presencia de la comprensión más bien cúltica del sacerdocio eclesiai. Esa presentación del sacerdocio de Cristo, en cuanto polémica, es necesaria; pero, por polémica, ha podido tender a ignorar al servicio de qué estuvo el sacerdocio de Cristo. Y eso es lo que se quiere recordar con el análisis teo-lógico de lo sacerdotal. 
2.1. Para delerminar to sacerdoral al nivel leo-lógico conem aamos con algo bien Iradicional: la necesidad de mediación entre Dios y los hombres. Su

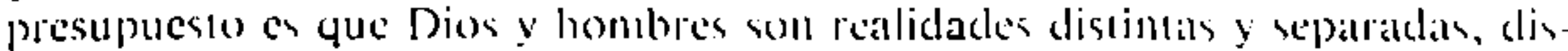
tancia que se comsuma con el pecado, y separación que es ausencia de salvación o positiva condenación. El problema del hombre es enconces cómo salvar csaldistancia, cómo acceder a Dios y encontrar en ello salvación.

l.a solución dacla a este problema por las religiones circundantes al mulldo biblico $y$, en parte, por el $\mathbf{A}$. $T$. es una solucion rilual. Ell hombre tiene que acercarse a Dios, pero para ello "no basta la perlección moral. porque semcjante perfecion deja al hombre en st munclo meramente humallo. Paral acer-

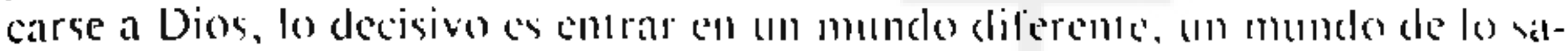
grado, Jo radicalmente distinto y separado cle lo profano, la esfera de lo divino y sobrenatural. Ahora bien, el hombe liene alceso al csal estera y a ese mundo mediante los ritos y cercmonias, que lo separan de lo profono y le hacen posible cl acceso al lo sagrado. ${ }^{-7}$

En este esquema de acceder a Dios el sacerdote es pica clave y decisiva. pues ćl realiza la inediación. El presupuesto para ello es que ćl es cl hombre de lo sagrado, separado de lo profano. El ámbito de esa mediación es el culto y. dentro de $\dot{c}$, su centro es el sacrificio, sobre 10 do el sacrificio expiatorio. Aunque en las diversas religiones, al menos las que rodean al mundo biblico, haya diversos matices, lo central de lo sacerdoral es hacer que el hombre sea purili. cado de su pecado, acceda a Dios y alcance salvación. Lo sacerdotal es lo mediador en este preciso sentido.

El A.T. y el N.T. mantienen el presupuesto anıropologico del hombre como ser separado de Dios y necesilado de salvación. El A.T. propone la solución cúltica al problema, aunque en tensión con ouro lipo de solución representada en las diversas alianzas que Dios hace con su pueblo. El N.T. proponc una solución radicalmente distinı y conlraria al problema del hombrc, porque radicalmente distinto es el Dios que aparece en Jesús. Lo que sea o no sacerdolal, lo que sea o no mediador, habrá que descubrirlo, en primer lugar, desde la novedad de ese Dios. Veamos cuáles son las caracteristicas fundamemales cle ese Dios por lo que roca al problema del hombre de acceder a Dios.

El Dios transcendente no es ya un Dios separado y lejano, sino un Dios ccrcano a los hombres; y esa sll ccrcania no ss súlo condición de posibilidad de su manilestación, sino contenido de su realidad: Dios da a conocer su realidad accreandose al hombre y quierc dar a comocer que (parte (c)) su realiclad es acercarse al hombre. Ese acercarsc le pertenece a su realidad y no es uno cnire ouro muchos posibles contenidos de la realidad misicriosa de Dios, sino conlenido central. Que cl acercarse a los hombres perlenece centralmente a la realidad de Dios se dice radical y sistemálicamente en la cncarnación: Dios noes ya sin ese su acercamiento; el Dios transcendente - que no deja de serlo, y por ello se le deberá comprender trinitariamente-es el Dios que se ha acercado.

Ese acercamiento de Dios es libre y gratuito; no depende de, ni puede ser Corzado por la voluntad de los hombres, ni tienen éstos que esforzarse para que Dios desee acercarse. Es un acercamiento activo, que busca llegar a en- 
contrar al hombre y no meraunente estar ahi. Es un acercaıniento permanente y no sólo momentáneo en Cristo; es un acercamiento incondicional e irrevocable que no depende de la respuesta clel hombre.

Ese acercamiento de Dios es bueno para el hombre y es lo sumamente bueno. Por trivial que parezca este recordatorio, aqui eslá lo central para comprender la realidad sacerdolal. Dios se acerca porque es bueno y se acerca como to bucno para los hombres. El mero hecho de acercarse no es sólo para estar más cerca y nocler asi juzgar inejor; se acerca más bien para salvar, porque ha oíclo los clamores de su pueblo y se ha acordaclo de él. El mero acercarse signilica que Dios ha rolo para sicmpre la simetria de ser posiblemente salvación o posiblemente condenacion. Dios se acerea, pues, para salvar y se acerca como salvador; Dios se acerca por amor y como amor. De ahí que Jesús presente el acercamiento de Dios como lo sumamente bueno para el hombre; el acercamiento en un 'reino' y el acercamiento como 'Padre,' expresiones de un Dios bueno para el hombre, que perdona su pecado, sana su corazón, lo humaniza y lo plenilica.

Ese acercamiento de Dios, tal como ha acaecido, es parcial hacia lo débil de este mundo, hacia los pobres, los despreciados, los pecadores débiles, hacia todos aquellos para quicnes vivir es una pesada carga. Esta parcialidad, en cuanto hecho, no es ulıeriormente analizable ni argumeniable; simplemente asi es, como lo muestran el A.T. y el N.T., y ese ser asi lorma parte del contenido central de la misma re en Dios. Pero esa parcialidad en el accrcamicnto de Dios muestra lo congruentc que es el que el amor de Dios se presente como misericordia y ternura, por dirigirse a los pequcños, y se presente como justicia, por dirigirse a los que son pequeños por ser oprimidos. Esıo no excluyc el universalismo salvífico de Dios, pero exige que ésle sea comprendido desde la parcialidad y no a la inversa.

Si la parcialidad del acercamiento de Dios no es ulteriormente analizable, se podria reinterpretar, sin embargo, como pedagogia de Dios para convencer al hombre de que es verdad que se ha acercado a ellos salvificamente, acercán. dose a aquellos a quienes nadic sc acerca y a quienes menos títulos parecieran tener - según los Hamados jusıos en tiempos de Jesús- para que Dios se les acercase.

El ámbito del acereamiento de Dios es la vida y la historia de los hombres en todo lo que éstos tienen de necesilados: de perclón y de curación, de pan y de esperanza, de verdad y de justicia. Dios no sc accrca separado de esa vida y de esa hisloria, sino en cllas; ni olorga la salvación separando al hombre de esa vida y de esa hiscoria, sino sanándolos, humanizándolos, potenciándolos y comunicándose a si mismo en ellas.

El Dios que se acerca sigue siendo el Dios santo y transcendente. Pero su santidad no es distanciamiento de lo histórico, sino máxima encarnación para que los hombres puedan llegar a ser "buenos del todo como lo es cl Padre celestial" (Mi 5,48); y su transcendencia no es sólo estar más allá de la historia - para relativizarla, como piensan algunos - sino activo atraimiento de la historia hacia sí, para que la historia dé más de si. 
Al acercamiento salvador de Dios se opone el mundo de pecado. Esto significa no sólo que unos no lo aceplan - como el jovell rico, y cobarde, que sc presentó ante Jesús-, no sólo que otros no agradecen ill acercamiento -como los leprosos curados desagradecidos-, sino que el mundo de pccado actúa positivamente contra ese acercamiento. Por qué sea eso así es el mistcrio último de la historia: por qué se rechaza activamente y se lucha a muerte contra lo que es sumamente bueno para el hombre, no ticne más explicación - sin serlo, pues es sólo poner un nuevo nombre al escándalo- que la hybris del hombre. quien quiere decidir en último término por si mismo lo gue es bueno parál.

Pero ese hacer contra cl acercamiento de Dios es asurnido por Dios mismo en su acercamiento y culmina en la cruz de Jesús. Esla muesıra, por una paric, que hay una oposición a muerle al acercamiento de Dios, que las clivinidades de la muerte -escándalo y locura, ayer como hoy - dan muerte al Dios de la vida; pero muestra, por otra parte, que el acercamiento de Dios es absolulamente real e incondicional, que Dios no sólo quiere ofreccr salvación, sino of recerse a si mismo por causa de esa salvación. De nuevo, no puede analizarse ulteriormente el hecho; pero, de nuevo, se puede reinterpretar como pedagogia divina para mostrar la absoluta seriedad y el absoluto amor de su acercamiento.

Porque Dios es asi cambia radicalmente el problema del acceso del hombre a Dios y la estructura del encuentro del hombre con Dios. No es el hombre el que accede a Dios en busca de salvación, sino que es Dios el que se abaja al hombre para ofrecérsela. El encuentro del hombre con Dios tiene entonces la estructura de activa respuesta, pero no de logro prometeico. Y esa respuesta se da en una doble dimensión. Por una parle, el hombre debe responder a Dios en agradecimiento, en fe y esperanza -cuyo contenido cenlral cs precisamente la aceptación de que Dios se ha acercado gratuitamente como salvación. Por otra parte, el hombre debe corresponder a la realidad del Dios acercado, convirtiéndose él mismo en buena noticia y salvación para olros, siendo él mismo expresión del acercaniento de Dios a los hombres, seguil la frase programática de Juan: "Dios nos ha amado primero... También nosotros debemos amarnos unos a otros" (1 Jn 4,9-11). En el aceplar, responder y corresponder al Dios que se acerca se realiza la salvación.

2.2. Todo lo dicho muesira que ha cambiado radicalmente la realidad de lo sacerdotal según las religiones y el A.T., porque ha cambiado su presupuesto básico y por ello queda abolido automáticamente cl sacerdocio antiguo aunque no lo hubiese mencionado la Carta a los Hebreos. En resumen, no hay nada creado que cause a la manera de la causa eficiente el acercamiento salvilico de Dios ni es necesario que lo haya. Pretenderlo - como lo pretendian los llamados justos en tiempos de Jesús - sería blasfemo estriclamente hablando, porque seria ir contra lo más profundo de Dios mismo y de su santidad. El sacerdocio antiguo es, por lo tanto, superfluo y atentatorio contra la realidad de Dios.

Según esto, ¿tiene todavia algún sentido descriptivo y especificante 
habblar de lo satcredolal al nivel teo-lógico? La respuesta positiva la ha dado el mismo Dios y no puccle, por lo tanto, ser clucubrada a priori. Dios mismo, para acercarse salvilicamente a los hombres, se ha proporcionado para si una expresión histórica de ese acercamiento que es Jesús y ha tenido que proporcionársela para accecler a los hombres en su historia e historicidad. Jesús es la expresión hisiorica por antonomasia del acercamiento salvador de Dios y por cllo mismo roda su realiclad es sacerdotal. Eso es lo que describen los evangelios sin mencionall la lerminologia sacerdolal y lo que explicita después la carta a los Hebreros usindo de esa lerminologia nero reinterpretándola desde la realidiad de lentis.

lisa realiclacl silterdotal al nivel teo-lógico siguc sicndo necesaria y posible. Es posible porcue posible es el proseguimienıo de Jesús y -en la convicción de la le porcutc sicmpre habra de alguna u oura lorma seguidores reales de Jesús. Esla es la condición de posibilidad del sacerdocio actual; recuerdo que podrá parecer innecesario, pero que es importante para que la condición de posibilidad no sea sólo el que haya sacerdocio verdadero desde Cristo, con recordar lo cual se contentan algunos, sino seguimiento real de ese sacerdote verdadero. Es necesario porque Dios quiere seguir accrcándose a los hombres y sigue necesitando expresiones históricas de ese acercamiento salvador.

Según csto polemos ofrecer una determinación teo-lógica de lo sacerdoIal, que deberá ser concrelada desde la crisıo-logía, pero que ofrece la ventaja, creemos, de proponer un concepto sistemático desde el cual se pueden determinar las acciones, las personas o grupos, los ámbitos, la espiritualidad y la verificación de lo sacerdotal.

Lo sacerdotal se relaciona por esencia con esa realidad concreta de Dios que hemos denominado su acercamiento salvifico a los hombres. Según eso, servicio sacerdotal al nivel leológico es $10 d o$ lo que ayude a expresar históricamentc csc acercamiento de Dios; acciones sacerdotales serán todas aquellas que lo expresen; sacerdoles scrán todas las personas y/o grupos que realicen esas acciones. Derivadamante, sacerdotal es todo aquello que ayude a responder y corresponder al Dion que se acerca.

Al decir 'derivadamente' no queremos, por supuesto, minusvalorar esa dimensión del servicio sacerdotal, pues es en el responder y corresponder de los hombres a Dios donde se constına la salvación. Lo decimos para mantener la primacia lógica que ticne el acercamiento de Dios, lo cual tiene una profunda consecuencia práclica. En cl servicio sacciclotal se deberàn usar diversos medios y argumentar cle cliversas formas, pero no cleberá faltar ni se deberá relativical el argumento supremo de la bondad de Dios, para que sea eso en definitiva lo que mueva a los hombres. Eso le impone ya una obvia exigencia a la exisiencia sacerdocal: haker presente la bondad de Dios y que esa bondad esté presentc en lodas las funciones liturgicas, doctrinales, parenéticas, seculares, etc., sin que éstas adquieran total autonoınia en base a su estructura. Se trata, en último término, de ayudar a que los hombres respondan y correspondan a Dios de la misma forma en que Dios lo ha hecho en Jesús: convencièndolos o venciéndolos desde clentro a base de un gran amor. 
2.3. Esta determinación del servicio sacerdotal es sistemática y teórica; no da cuenta nor ello de muchas cosas concretas de esc servicio. Pero por ser una determinación reo-lógica es imporlante y decisiva. A conlinuación vamos a enumerar las consecuencias que se derivan de esa determinación sisicmálica. Las vamos a exponer de forma positiva, aunque pudieran ser lambién polémicas. Lo que hay que añadir es que si fuesen disculibles, la discusión debiera mantenerse en el plano teo-lógico (y cristo-lógico) y no argumentár clesde luera de él para descalificarlas; y si son correctas, entonces deben aplicarse a cualquier forma del cjercicio sacerdolal concreı. En nuestra opinión aqui esı́ en juego la comprensión del servicio sacerdolal y su práctica concretia.

El servicio sacerdotal es printariamente y en directo apostólicos; su destinatario es el mundo como correlato último de Dios. Esto significa, negativamente, que no se debc comenzar melodológicannente con el cjercicio del sacerdocio intraeclesial - por necesario e importante que sea - para comprender su esencia, sino con el envio al mundo, lal como lo exponc el Vaticano Il al presentar el sacerdocio de Cristo (PO 2). La apostolicidad de lo sacerdotal se deriva de la misma naturaleza del asunto, de la misma realidad de Dios y no se decide sólo a partir de unos textos - aunque haya muchos en el N.T. que lo recalquen - como si fuese una arbitraria decisión de Dios.

Positivamente, y teniendo en cuenta la siluación lalinoamericana, tres cosas deben decirse del destinalario del servicio sacerdotal. L.a primera es que por su esencia se debe dirigir al mundo de los necesirados, de los que más necesilan salvación, juzgando desde Dios quiénes y por qué son necesilados y jerarquizando desde Dios esa necesidad; es la expresión cle la parcialidad del acercamiento de Dios desde la cual se podrá alcanzar la universalidad del desıinatario. En segundo lugar el servicio sacerdolal debe dirigirse a los necesilados no sólo en cuanto personas individuales, sino tambièll en cuanıo mundo de los ne. cesitados, es decir, necesidades que configuran todo un munclo, en el sentido en que se habla del pecado del mundo. Este mundo podrían ser millones de seres humanos en el llamado primer munclo, deshumanizados por la abundancia. desresponsabilizados de la miseria de la humanidad, con sus subproduclos de sin sentido o angustia. En el tercer mundo no cabe dida de que existen millones de seres humanos que viven en un mundo de miseria y opresión. Esıos mundos son los que se ofrecen al servicio sacerdolal y si se mencionan es para superar la tentación comprensible al intraeclesialismo cuando estos mundos. por su novedad, su peligrosidad, su antagonismo o su desentendimiento, según los casos, suponen una seria dificultad para la lglesia. Abandonarlos, por cualquier razón, seria prolundamente a-sacerdolal; refugiarse en la lglesia para defenderse de ellos sería anti-sacerdoral.

En tercer lugar, existen otros grupos socio-politicos en el tercer mundo que se presentan como salvadores. De ellos, unos proponen una salvación histórica dentro del mundo occidental y según lo que se han considerado sus valores tradicionales; otros los Ilamados revolucionarios, proponen otro tipo de salvación histórica. No es ahora el momento de analizar tan complejo problema, pero si de hacer unas reflexiones sobre la actitud sacerdolal hacia ellos. 
Por una parte hay que analizar desde la realidad de Dios y no desde el presupuesto de que sólo un determinado mundo -el occidental- es el mundo de Dios, la afinidad y convergencia y lambién las diferencias entre la salvación que ofrecen esos grupos y la salvación de Dios. En lo posible, es sacerdolal el trabajo para que la salvación que desean traer esos grupos sea convergente con la salvación de Dios. Por olra parte $-y$ éste suele ser el problema más frecuente- la lglesia no puede desentenderse de los grupos liberadores o revolucionarios y cierlamente no puede hacerlo apelando a lo sacerdolal. Esos grupos pueden asustar a parte de la lglesia por su novedad. radicalismo y lambićn por el desenmascaramiento que hacen de la lejesiat; pero nada de eso implica que haya mayor servicio sacerdolal porque sea menor la alención a csos grupos. El intento de evangelizar sus proyectos desde dentro, es tambièll sacerdotal. Por razones históricas de credibilidad, a la Iglesia le va mucho en ello y si esos grupos fuesen tenidos como malos - cuando se les declara marxistas se les tiene automáticamente como el mayor peligro para la Iglesia-, cntonces recuérdese al menos el ejemplo de Jesús de ir a la búsqueda de los perdidos.

No es nuestra intención aqui tratar esla problemática, sino esclarecer la apostolicidad de lo sacerdotal. Al menos debiera quedar claro que no se es más sacerdotal cuanto menos se va al mundo; no se es más santo cuanto menos se va a lo peligroso del mundo; no se acerca más a Dios por estar menos incontaminado del mundo. Al menos debiera quedar claro que al nivel reo-iógico el analogatum princeps del servicio sacerdotal está en el servicio al mundo necesitado de salvación, para que no ocurra que en nombre de lo sacerdotal se sca anti-sacerdotal o, en las palabras de Ch. Peguy "porque no lienen el coraje de ser del mundo creen que son Dios ... porque no aman a nadic creen que aman a Dios."

Portador de lo sacerdolal a este nivel teo-lógico es todo aquél, hombre o mujer, individuo o colectividad, que exprese históricamente el acercamiento salvador de Dios. En este sentido, pudiera hablarse en estricla lógica incluso de un sacerdocio anónimo, asi como se habla de cristianos anóniınos. Pero dejando de lado esta problemática, hay que recalcar que porlador de lo sacerdotal es quien acerque a Dios prosiguiendo la obra de Jesús. Por esıa profunda razón pudo el Vaticano Il reafirmar el sacerdocio común de todos los bautizados, aunque después lo di Cerenciase del de los ordenados.

Dos consecuencias importantes se deducen de ahi. l.a primera es que el portador de lo sacerdotal a este nivel teo-lógico debe comprenderse desde lo que realmente hace al servicio del acercamiento de Dios y no a la inversa. La segunda es que la Iglesia debe plantear lo sacerdotal no sólo desde los sacerdotes en cuanto individuos sino desde ella misma en cuanto comunidad y pueblo de Dios. Una Iglesia sacerdotal no es lo mismo que una Iglesia con sacerdotes, aunque la realidad de éstos in (nuirá mucho en aquélla y la acción sacerdotal dependerá - como se esclareció en la lglesia salvadoreña en tiempos de Mons. Romero- de la acción de toda una Iglesia. Es la acción de loda una Iglesia la que decide - y así lo captan los pueblos - si se ha acercado Dios.

El servicio sacerdotal es evangélico en el sentido originario del término: 
comunicación y realización de una bucna noticia. Servir al acercamiento de Dios a los hombres es realizar lo bueno y lo sumamente bueno. Este recordatorio pareciera ser trivial, pero es importante hacerlo para comprender la formalidad del servicio sacerdotal: se trata de hacer el bien comunicando lo bueno de Dios. Que ese Dios acercado sea bueno para el hombre aparece en los dos tèrminos claves que usa Jesús: Dios se acerca como 'Padre,' suma bondad, misericordia y ternura, y ese Dios se acerca en un 'reino' cuyo contenido es la utopia de la humanidad: justicia, paz, libertad, fraternidad. Acercar a Dios es llevar lo bueno al corazón del hombre y de la sociedad, sanarlos, humanizarlos y potenciarlos.

Pero también es bueno para el hombre que el Padre se acerque como Dios y el reino acercado sea el reino de Dios. Se le acerca una bondad plena, que no puede por lo tanto ser acogida adecuadamente; pero que en su plenitud anima al hombre siempre a no pactar con sus creaturidad, a que dé siempre cada vez más de si, a que la transcendencia de Dios y la utopia del reino lo muevan sicmpre a una mayor plenificación. Ese acercamiento de Dios-Padre y de un reino-de-Dios es lo que sana, potencia y plenilica al hombre; le humaniza y le anima a una siempre mayor humanización, a recibir lo bueno y a realizarlo, sin poner limites ni a la recepción ni a la realización.

Este servicio al acercamiento 'bueno' de Dios es la Tormalidad del servicio sacerdolal. Esto no significa quitar agudeza a las iremendas exigencias del Dios bueno, pues precisamente en base a ese Dios se le hacen al hombre las mayores exigencias: ser buenos del todo como el Padre celestial. Pero significa que el servicio sacerdotal anima al hombre a cumplir esas exigencias confiado en último término en la bondad de Dios, como aparece programáticamente en las escenas evangélicas del perdón en las que el pecador cambia y se convierte vencido por el amor de Dios.

Tampoco significa quitar agudeza a la denuncia profética y a la condena a los opresores, sino más bien exigencia mayor de denuncia y condena a quienes se oponen y hacen contra esa bondad, pues ello atenta contra la más profunda realidad de Dios. La denuncia y la condena es servicio a la bondad de Dios para defender a los débiles a quienes tanto ama, y también buena noticia sub specie conırarii a los opresores. La denuncia en el servicio sacerdolal debe surgir de la convicción de la bondad de Dios y es por ello tanto más decidida en favor de los oprimidos y tanto más dura hacia los opresores.

Que el servicio sacerdotal sea formalmente evangélico significa en último término que quiere comunicar la bondad de Dios y que esa bondad es su última argumentación y motivación. Que tenga éxito o no es otra cosa, pero si el servicio quiere ser sacerdotal la comunicación de la bondad de Dios debe estar presente en las actividades pastorales, parenéticas, litúrgicas y teológicas.

El ámbito o los ámbitos del servicio sacerdotal deben ser determinados desde el ámbito o los ámbitos en los que el mismo Dios se acerca, sin dejarse llevar, sobre todo en este punto, por la lógica del ámbito de lo sacerdotal en las religiones y en el culto. $A$ priori pudiera decirse que ese ámbito es totalizante, pues es 'Dios' quien se acerca; y, además, asi se constata a posteriori. Recalcar 
la Iolalidad de cse ámbito es cle suma importancia pitra no cacr en la tentación de reducir el servicio sacerdotal a algo regional y, menos, comprender su esencia desde lo regional.

Descriptivamente, como lo muestra lodo el A.T. y el N.T., puede decirse que el acercamiento salvador de Dios acaece en el ámbito de lo personal, de to histórico-social y de lo total. Dios se acerca a lal persona perdonando al pecador, cambiando su corazón de picdra en corazón cle carne; dicho de forma sintética, asemejandólo a lesús y asi divinizándolo. Dins se acerca social e históricamente liberando a un puchlo, cambiando estructuras cle opresión en orras de liberacion ("yue construyan casas y las habiten, que urabajen los campos y coman de sus lrutos"), estrucluras de guerril en otras de paz ("que de las espadas hagan a/adones"), estructuras de marginación en otras cle fraternidad ("que el lobo y el cordero coman juntos"), estructuras religiosas impotentes en otras eficaces ("antes de que me hablen yo respondere"). Dios sc acerca a la totalidad humana, social y cósmica hacienclo una alianza con un pucblo y con toda la humanidad, creando nuevos cielos y nueva ticra, llegando a ser al linal rodo en Iodo.

Ambitos del acercamienı de Dios son cnlonces ıdos aquellos ámbitos en donde Dios quiere que se realice su voluntad salvifica y se conoce que se ha acercado en cualquiera de esos ámbitos cuanclo esa voluntad se ha realizado. Puede preguntarse, sill embargo, si cxisıe una jerarquización en los ámbilos del acercamienı de Dios, pregunta nada leórica, pues desde ahi se suele delerminar lo específicamente sacerclotal y jerarquizar las aclividades sacerdolales. El presupuesto de la posible jerarquización eslá en la dualidad -o pluralidad - de las dimensiones de lo humano y en la dualidad de la condición de lo humano. como lo necesitado de salvación y como lo capacilado para dar màs de sí.

Esa diversidad puede ser comprendida dualistamenle, y en ese sentido la hisıoria ha mosırado clara preferencia por el acercamienıo de Dios a lo espiritual, personal y transcendente del hombre. Sin embargo, en los evangelios no aparece el enfoque dualisia del acercamiento de Dios sino el complementario. Por Iomar los dos símbolos claves para Jestís, 'reino' es una realidad histórica y social: pero no sólo eso. Es también propiciador de valores espirituales, como la hermandad y la reconciliación: y dehe ser construido con valores espirituades. 'Padre' es el símbolo del acercamiento de Dios al corazón del hombre, pero no sólo eso. Dios se acerca curando las enfermedades del cuerpo. Al 'Padre' hay que pedirle el perdón de los pecados, pero lambién el pan nuestro de cacla día.

Que existe complementaridad on los dos ámbitos del acercamiento de Dios se comprende más claramente si se recuerda la parcialidad de Dios hacia los pobres. Si se universalizase desde el principio conceptualmente $-y$ asi se deshistorizasc - el destinatario del acercamiento de Dios, entonces, lo corporal y social, alli donde ya estuviese garantizada suficientemente su realidad, podrían aparecer sólo como ámbitos preparatorios para el verdadero acercamienlo de Dios en el corazón clel hombre. Pero si Dios se acerca en directo a 
los pobres, enlonces cse ámbito recobra nutcha mayor imporlancia. Qus Dios se acerque salvificamence a los pobres no puede ser dicho ni hecho si su acercamiento no es también para salvarles de su pobre/a, lal como aparece én Jesús y con ultimidad, y lal como se ha reconocido en A.l.. al hablar de la necisidad absoluta de liberación.

l.a razón intrinseca de esa necesidad essa el que pobreza dice relación al la muerte y salvación dice relación a la vida. "Vida' no sigmbilia acpui solo lo corporal, en diferenciación de lo espiritual; dice la realiclad mas primigenia del hombre, la participación primaria en la realidad de Dios, st crealdor, descle lá

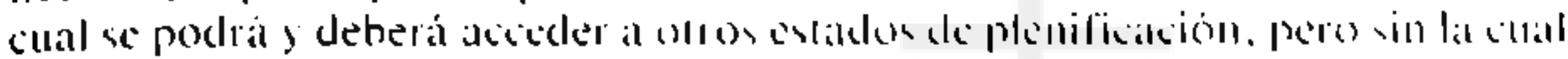
la mistnal creación cle Dios está amenazadal y viciada. ¿Puede, en verdad, acercarse un Dios amoroso, un Dios Padre y liberador. a las mayoriats de pobre.. oprimidos y crucificados, dejando intocada sll miscria, marẹinacion y' merte? ¿Es ese acercamiento de Dios algo secundario, provisional a ládico?

Desde el acercamiento de Dios a los pobres el problemal de la jerarcjuidacion de los ambitos se complejiza. pero lambićn se esclarece; no puede ser résuelto simplistamente dands prelerencia a lo espiritual y personal, sobre lo corporal y social. Visı desde los pobres a quienes Dios se acerea os cridente que lo captan como salvador, cuando lo caplan como su delensor y liberador, como propiciador de su vida - aunque sean ambién los mismos pobres los mejores cjemplos. inuchas veces, de que esa salvacion de loios se operá en lo profundo de sus corazones, cuando se convierlen de su resignacion pasada, de sus pecados, y cuando se convierien a la esperanza, a la solidaridad, al desprendimiento y a la entrega hasta de su propia vida. Visıo desde Dios, pudiera preguntarse, en un cjercicio puramente especularivo, si Dios se acerca con un reino. liberando to malerial e hisiórico. para ame despucis los nobres le puedan aceptar como Padre, o, si por se" Dios in'lle ame acercerse a si mismo" conjuntamente con un reino de liberación. En los evangclios no aparece lal disyumtiva, sino que ambas cosas son expuestas con sencilley y ultimidad porquc asi es Dios y asi es el hombre, necesilado de reino y de Padre, llamado a res. ponder al Padre y a construir y vivir en un reino.

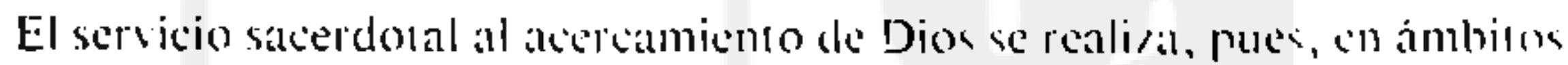
diversos y complementarios, que se remiten dialecticanente el uno al olro. La finalidad ultima de ese servicio es al aceramiento absoluto de Dios, cuando Cristo entregue el reino al Padre (1Cor 15.25$)$ y Dios sea lodo en lodo $11 \mathrm{Cor}$ 15.28). Ahi se dará el pleno acercamiento de Diox y la salvación absoluta de in. (lo el hombre y de lodos los hombres. Pero en la historia ese servicio sacerdolal se va haciendo de servicios parciales: hay que acercal a Dion al coraron del hombre y hay que accriarlo a su realidad material y social. I.os signos de los lienjpos sugieren la pedagogia profunda de cese servicio. Fon Amćrica l_alina es evidente que dificilmente se podrá hablar de acercamiento de Dios, si no se ponen signos cle que ese Dios quiere la vida y no la muerte de los pobres. Y los pobres captan y sienten que Dios se les ha acercado cuando ven esos signos. Entonces, además, sienten con más profundidad la necesidad de que Dios se les acerque al fondo de sus corazones. Muchos cjemplos podrian aducirse en 
Favor de esia afirmación, pero baste con mencionar lo que ocurre en los relugios de la Iglesia en El Salvador, cuando los pobres reciben conjunlamente pan y eucaristía, alrabetización y catequesis, precencia lisica y esperanza. En esa globalidad captan que Dios se les ha acercado y los elementos concrelos se refucrzan inutuamente para comunicar el accrcamiento de Dios. Y ese acercamiento del Dios bueno es lo que les motiva a preguntarce por y realizar su propia bondad, a intentar ser buenos de lodo. Aqui aparecen unificadamente los diversos ámbilos del accrcamiento de Dios: pero lo importante es la conclusión: los pobres sicnten que en verdad Dios se les ha acercado, que cse acercamiento es bueno para ellos y gue les mueve a ser huenos ellos mismos.

El hugar del servicio sacerdotal es la historia real y no un lugar separado de esa historia, como lo inuestran los evangelios y lo cxplicita polémicamente la carta a los Hebreos. Dios se acerca a los hombres en su vida c historia concretas; lo cual vale para su realidad material y social, pero también para su realidad personal y espiritual. Según esto el servicio sacerdolal no puede ser religiosista, en el sentido de propiciar ulla comunicación con Dios mecánicamente, ni cúltico, en el sentido de propiciarla en un lugar separado. Sin embargo, pucde y debe ser religioso y cxpresarse en una liturgia.

El sentido de estas precisiones terminológicas - sca cual fucre la fortuna de los términos clegidos- es el siguiente. Acercar al Dios bueno para el hombre sólo puede hacerse a través de bondades concrctas, cosas y acciones que muestren que hay bondad en Dios. En el servicio sacerdotal hay que acercar a Dios, por lo Ianı. Esıe sc acerca conjuntamente con realidades hisıóricas: el perdón y el pan, los signos de misericordia y las práclicas de justicia, las muestras de esperanza y la invitación/exigencia a la propia conversión, a una nueva vida, elc. Sin eso histórico concrelo no se puede comunicar la salvación de Dios, y por ello, el servicio sacerdotal liene que ser histórico y mundanal. Pero, por otra parte, como no es cualquier bondad ni cualquier salvación la que se quiere comunicar, sino la bondad y salvación de 'Dios.' lo bueno concrelo tiene que ser realizado como abierlo siempre al 'más,' y de ahí la necesidad de que lo bueno concreto vaya acompañado de alguna palabra o gesto que exprese esa apertura. Hacer y ofrecer lo bueno, desde un punto de vista sacerdotal, significa hacerlo y ofrecerlo abierto a una bondad siempre mayor; y abierta a lodos los ámbilos en que Dios quiere acercarse. Esa es la forma hisıórica de que a través de lo concreto se pueda hacer presente una mayor bondad, que apunta asintólicamente a la bondad de Dios.

Esto es lo que queremos expresar al decir que el servicio sacerdotal debe ser religioso, acercar a un Dios que es Padre y, por lo limı, bueno para el hombre; pero a un Padre que sigue siendo Dios y, por lo tanto, mayor que las bondades concretas en las cuales necesariamente tiene a que acercarse. Por ello el servicio sacerdotal debe ser histórico y no religiosista, pero debe ser religioso en cuanto abierto a la mayor bondad y sin ponerle limites en nombre de las bondades concretas.

Por ello tambièn el servicio sacerdotal no puede ser cúltico, en el sentido convencional de separado; pero pucde y debe expresarse en una liturgia. Por li- 
turgia entendemos aqui el lugar en donde se explicila, se agradece. se celcbra el acercamiento bueno de Dios y en donde se enfatiza que es cle Dios. Por ello, lat liturgia es también el lugar de pedir por el advenimiento (le esc 'más' y' el lugar del arrepentimiento por haberlo empequeñecido. Liturgia no se oponc a historia, sino que la su-pone y la pre-dispone al más: no es separación de la historia. sino ahondamienı en ella para explicitar su significado más profundo y su capacidad de dar más de si. Por eso el servicio sacerdolal puede y debe realizarse tambièn en la liturgia.

El servicio sacerdotal, tal cmo lo hemos descrito posibilita y exige una clererminada existencia vespirilualidad. las cuales deberin sel concredaldas dende Cristo. pero que se desprenden de lo ya dicho.

La espiritualidad sacerdotal debe ser formalmente apostólica y misionera para llevar a Dios a los hombres, con el importante maliz cle salir a buscar a los hombres y a los más necesitados. "Ay de mi si no evangelizare," dicc Pablo. Debe tener en cuenta a los más necesitados de salvación, a los pobres, a los perdidos de la casa de Israel o a los paganos del liempo de Pablo, con las traducciones actuales de pobres, perdidos y paganos. Negativamenic, debe superar la tentación del intraeclesialismo y mucho más la de abandonar al mundo a su miseria, bien por incapacidad o miedo, bien por temor a no contaminarse con el mundo real de la política, de los conflicios y las revoluciones. Cuando surge ese temor, ingenuo o hipócrita según los casos, conviene recordar el ejemplo de Jesús comiendo con publicanos y prostitutas, si por ello se les t11viese.

Debe ser una espiritualidad basada en la honda convicción de que cl acercamiento de Dios es bueno para el hombre y la hisioria, que con Dios se humaniza más y mejor el hombre y la historia, pero todo ello sin rutina, por convicción. De ahí se deduce, por una parte, el descentramiento de la propia persona o de los grupos sacerdotales, pues no desean comunicarse a sí mismos - siempre se ha dicho que el sacerdote no actúa cn su propio nombre sino in persona Christi- sino a Dios. Y, por otra, el desvivirse para que ese sumo biell que es Dios se acerque realmente a los hombres hasla los excesos de Pablo: "Quisiera ser anatema por la salvación de mis hermanos."

Debe ser una espiritualidad dispuesta a la conflictividad porque la buena noticia no puede ser dicha y hecha sin denuncia de la mala realidad y sus propugnadores y sin que éstos reaccionen contra el servicio sacerdolal. De ahi la disponibilidad a la profecia - con el convencimiento de que eso es también bueno para el hombre- y a la persecución, la necesidad cle fortaleza para mantenerse en los conflictos y llegar a ofrendar martirialmene la propia vida.

Debe ser una espiritualidad testimonial de modo que el portador dc lo sacerdotal pueda ofrecer ya en sí mismo, con Ioda modestia y humildad, que es bueno que Dios se haya acercado; y de modo que pueda generar credibilidad - cada vez más piedra de loque del servicio sacerdotal-. ayudando asi a que el Dios que se acerca pueda ser aceptado y correspondido, pueda invilar a y exigir esa respuesta. Parte importante de ese testimonio es la crealividad y libertad, como condición para expresar que es 'Dios' quien se acerca, quien 
vienc por los caminos que él quiere, viejos o nuevos; como expresión del desvivirse nara que Dios realmenle se acerque.

Fs una cspiritualidad que debe generar un servicio sacerdolal hacia personas concrelas, pero lambièn hacia mundos enteros necesitados de salvación; que, pot lo lanto, debe gencrar una mirada de misericordia y una respuesta eficaz a las necesidades de personas concretas, pero también de pueblos enteros. De ali tambièn la disponibilidad a trabajar no aisladamente, sino dentro del colegio sacerdoral -en el sentido restringido y en el sentido amplio de Ioda una leglesia sacerdotal- para poder accral a Dios más eficazmente. De ahí, la glandeza de corasón para relativizar los propios ćxitos y fracasos en lavor del évilo de colat una Iglesia sacerdotal o a la luz del fracaso fundamenla!.

El servicio sacerdotal necesila una verificación histórica. Al hablar de verilïcación mos l'clerimos a lo que, de hecho, ocul're a posseriori después del servicio sacerdolal. $A$ priori se pudiera decir, por supuesto, que el querer acercarse de Dios es incondicional c indefectible - como lo expresa, entre olras cosas, la teoria del ex opere operato; a priori se puede decir que el servicio sacerdotal requiere una llaınada y un envio de Dios; a priori lambién puede determinarse el tipo de existencia, espiritualidad y actividad sacerdotal. Todo esto es importante tenerlo en cuenta, pero no resuelve todavia la pregunta por la verificación. Dicho con loda scncillez, el acercanmiento salvador de Dios ocurre cuando ocurre. Cuando Jesús bendice al Padre porque los pequeños han entendido el reino, cuando despide en paz al cnfermo curado o al pecador perdonado, cuando declara que la salvación ha cnırado en casa de Zaqueo, etc., su servicio sacerdotal ha sido eficaz.

La importancia de recordar esto tan evidente está en que el servicio sacerdotal puede fracasar. El liacaso se puede deber a los destinatarios o a los porladores de lo sacerdotal o a ambos. Pero es importanle preguntarse en cada caso por quic, porque esto es sumamentc imporiante para la pastoral. Dejando a tII lado el posible fracaso debido al destinatario, hay que preguntarse por qué una determinacla actividad sacerclotal ha tcnido éxilo o ha fracasado. Pero lo primero que hay que hacel es reconocer humildemente, verificar, si hay exito o liacaso. Con esto queremos decir que, además de las condiciones a priori para el cjercicio sacerdotal, hay que analizar a fondo sus resultados.

Empezando por to negativo puede ser que, o por un pecaminoso ejercicio del servicio sacerdolal o simplemente por inacapacidad, aun con buena volunlad, la lglesia no acercuc a Dios a los hombres. De hecho, asi ha ocurrido en Europa entre los intelectuales, el mundo obrero y ahora. cada vez más, incluso entre las clases medias. Dicho positivamcnte, se puede constatar que varias Iglesias en América I.alina hall acercado a Dios a muchos pobres, han reafirmado la le de dubitantes o, por lo menos han devuelto seriedad al problema de Dios entrc intelectuales alejados o agnósticos.

Indudablemente sólo Dios sabe si y cuándo él se ha acercado a los hombres. Pero juzgado exteriormente, tampoco se puede suspender indefinidamente un juicio. Pero lo que de aqui se deduce nara nuestro proposito es que 
no se puede presuponer sin inás que ya se conocen los molon -la pasioral en sentido amplio- para acercar a Dios, sino que hay gue aprencler !o guc realmente ocurre. $Y$, a la inversa, de quic hay pastorales novedosas. Lantav recer juzgadas como arriesgadas y peligrosas, que si alcercan a Dion a lis hombres. El movimicnto de sacerdotes obreros, las nuevas Iormas de homilias de Nons. Romero, la pastoral de acompañamiento a quienes perlenecen a comunidades de base y a organizaciones populares cte., si parces cue ham acercislo a Dios. Estas pastorales han sido novedosas, a reces enidar por hecorudovas. pero han sido eficaces.

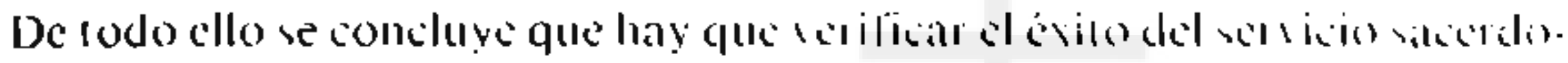
tal y no presuponer que se da automáticarnente porcue ya se sabe cómo alcall. zarlo. Seria muy triste y desastroso para la lgetesia cute apliciase a lo siccerdolal

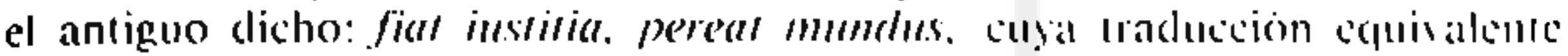
scria: hágase lo sacerdolal como ya sabemos, allncluc cadla ve vea mis irrele. vanle para el mundo.

Y como en coda verilicacion. lo posiliso se devenbre bambien dende st contrario. Para preguntarse si hay servicio sacerdolal elicaz hay quse pregulltarse cuándo hay un servicio a-sacerdotal o anti-saccerdotal, atun en medio de muchas actividades convencionalınenle sacerdotales. Si se extiende el desinterés por Dios y sul acercamiento, si el anumcio de Dion no es iaplaclo como buena noticia, entonces - con mejores o peores infencione-- el icricio hia sido a-sacerdotal. Y si. neor alin, la reacción a ese servicio liuese lo yue se repile en la Escritura: "Por vuestra causa es blaslemado el nombre de Dion entre las naciones." entonces habria sido anti-sacerdotal.

Repelimos que el análisis de la verilicicción debe inchuir la alciilud del deslinatario, pero no debe excluir la de los portadores de lo sacerderal. Si se quicre ser eliea/ sacerdolalmenie no hasta nor lo limbo con delinir su realiclad a priori ni con ofrecer a Dios, ell la intención. las diversas actividades parar que sean sacerdotales. La verificición a posteriori es sumamente importante por honradez hacia Dios y para clesarrollar una pasıoral sacerdotal clicas.

2.4. Con las reflexiones y precisiones anteriores podemos afreser la siguiente sintesis. El servicio salerdoral al nivel teo-logico en el servicio de expresar históricamente el acercamiento salvador de Dios a los hombres y la res. puesta de los hombres al Dios que se acerea. Esta determinacion. por ser teo. lógica va más allá y engloba la dislinción consencional entre salcerdecio combin

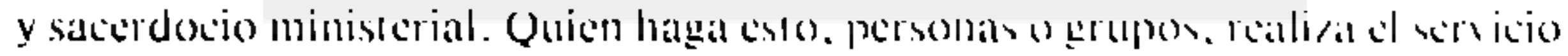
sacerclotal, y cualquier otro sacerdocio, comint o minisleriall, debe ser comprendiclo descle ahi.

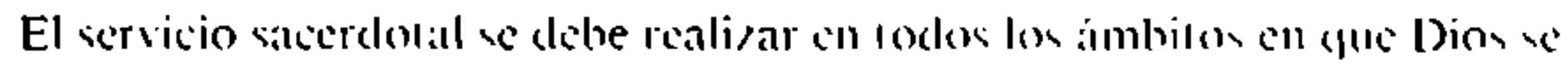

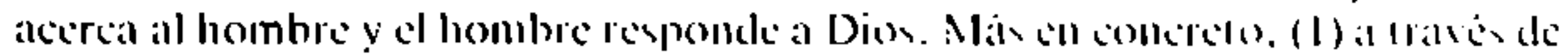
la palabra que enuncia y anumcia la realidad salvadora de Dion, sacande al hombre de su ducla sobre Dios, de su posible angustia o deserperición acerea de Dios y desenmascarando su innata tendencia a liabricar sus propios diosex: (2) a través de la realización del contenido de esa palabra. del amor de Dios que se acerea como Padre y que se acerea en un reino: (3) a lrave de la lilureia 
en la que se escuche y explicite la palabra, antigua y mucva, del Dios que se accrea. Del otro lado, cl servicio sacerdolial se realiza, (1) en la mysiagogia para que lon homber acepten esa nucva, incesperada y escanclalosa noticia de Dios, pero laınbién I ransformante y buena; (2) en la invilacion/exigencia a que los hombres respondian y correspondan al amor de Dios en el amor a los hernanos, en todos los niveles en clué éstos necesitan salvacion: (3) en la ayuda a expresar liturgicamente la respuesia al Dios acereado, con go/n collando se ha réalizado ese acercamienı, con arrepentimicno cuando se ha viciado por cul-

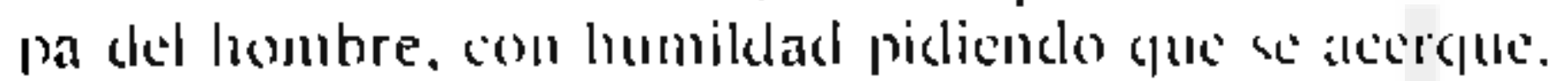

Ambor servicion deben realizarse con la parcialidad hateia lon pobsen y debiles, lal como el mismo Dion se acereib, con la dieponibilidad a introducirse en los confliclos historicos fuc ese servicio origina y con lat lortalèa a mantenerse en la persecución que los dioses de las malas realidades llexan a cabo contra los que hacen presence al Dios de la buena nucia.

\section{La dimensión cristo-lógica de lo sacerdolal}

Todo lo dicho anteriormente presupone. por supuesto, la realiclad de Crisıo. Explicitar alocra su sacerdocio. la dimensión crisı-lógica de la realidad sacerdolal, es sin embargo, importante para concrear y asi esclarecer lodo lo anlerior y para verilicar (o corregin) si lo dichn alles ha sido correcto o excesivamente a priorista desde la realidad de Dios. Más ell concrelo, es imporlante para determinar normativaniente la existencia sacerdolal, comprender el sacerdocio intraciesial desde el de (risto y no descle las religiones, lentación nerenne para la Iglesia.

3.1. Corro es sabido, en el N.T. . con la excepción de la carla a los Hebreos, no se usa cl término sacerdote (hierens y derivados) para devcribir la persona y misión de Jesuis. Cuando aparece el término en el N.T. se aplica más bien, con rarisimas excepciones, al los sacerdoles paganos y a los del $A$. T. Una de esas excenciones es la explicación coue da Pablo de su anosiolado: "mi fumción sara comsiste e'l amuncian la huena nolicia de Dios" (Rom 15,16), con lo cual reinterpreta lo sacerdotal en la linea teo-lógica antes explicacla.

En los evangelios Jesús es presentado como laico perteneciente a la tribu de Judá, y no a la de l.evi. De mayor significado es cue en la interpretación tcológica que los evangelios hacen de Jesis, éstos le aplican diversos títulos honorificos pero no le aplican el titulo de 'sacerdole.' aunque en el tiempo de Jesús la esperanza mesiánica se expresaba también con la aparición del delinilivo sumo salecrdote.

En el resto del N.T., con la excepción de la Carta a los Hebreos, lampoco se le demomina sacerdote, aunque en la reinterpretación de su obra salvilica se aluda ya a conceptualidad cúltica: "nuestro cordero pascual ha sido immolaclo" (ICOr 5.7); se use de la tipología del "cordero reconciliador" (Ap 5,9); se mencione la "sangre" de Cristo que apunta al sacrilicio (Rom 3,25; 5,9; Ef 1,7;2,13; cfr. también los evangelios: Mc 14,24 y par). Pero en conjunto Jesús y su obra pudieron ser comprendidos sin apelar a la conceptualidad y terminología sacerdotales. 
Y, sin embargo, la realidad de Jesús fue sacerdotal, plenamente sacerdotal y la única absolutamente sacerdotal, como dice la carta a los Hebreos. Antes de analizar esta carta creemos convenienle volver a las narraciones evalngelicas, pues en ellas aparecerá concretamentc lo que la carta dice sistemáticamente del sacerdocio de Cristo, y en ellas aparecerá lo que ankes hemos llaınado el servicio sacerdotal teo-lógico. Aunque ya sea conocido. hagamos un breve resumen de la persona y misión de lesús desde la perspectiva sacerdotal teológica.

Jesús aparece anunciando el acercamicnto del reino de bios como blena noticia y el acercamiento de Dios como Padre bondadoso, lo cual ocurre graciosamente y como pura iniciativa de Dios. Jesuis insiste en que asi es Dios, lo cual muestra positivamente en las parábolas del amor de Dios. cn sus acercámientos concretos a los pobres y pecadores; y negativamente en las controversias, denuncias y desenmascaramient os de quienes no quicren que Dios se acerque gratuitamente como Padre y quienes aclian contra el reino de Dios oprimiendo económica, política y religiosamente. En palabra y obra recalca que ese acercamiento del reino y del Padre es para los pobres y peçueños y para los pecadores según la ley.

Toda la actividad de Jesús está guiada por el servicio a ese acercamiento de Dios. De ahi sus milagros y exorcismos, el perdón de los pecáclos, su aciividad predicadora y orientadora, su acercamiento concrelo a pobres y pecadores; y, por otra parte, su actividad denunciadora, desenmascaradora y de controversia. En una palabra, Jesús se desvive para mosirar que Dios sc acerca en su reino y se acerca como Padre.

También la actividad de Jesús éstá guiada por el cleseo de ayudar a que los hombres respondan y correspondan al acercamienlo de Dios. De ahi, sll exigencia a la conversión, al seguimiento, a praclicar la oración y el mandamiento del amor, a corresponder a Dios con el espiritu de las bienaventuranzas, elc. Pero lodo ello, no como pura y fria exigencia, sino como respuesta al Dios acercado, que es respuesta costosa pero gozosa, como la de quicn ha cncontrado la perla preciosa y el tesoro escondido.

Jesús celebra el que Dios sea asi y el que se acerque. Se alcgra cllandolo lon pequeños le han conocido o la salvación llegó a casa de Zaqueo y puso gestos festivos de ese acercamiento en sus comidas.

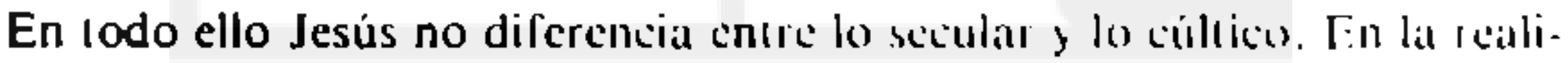
dad concreta de su tiempo, Jesús no vio lo cúltico como lugar de acceso privilegiado a Dios ciertamente; sino más bien como lo sospechoso y viciaclo. Jir is opuso a una concepción ritual de la relación del hombre con Dios y a una manera externa de entender la santificalcion: "Misericordia ytuiero y (II) sacrificio" (Mt. 9,10-13; 12,1-3; 15, 1-20; J1 5,16-18; 9, 16 elc.). Sul obsesión. si asl se la puede llamar, fue más bien la de acercar a los hombres en cualquier forma y en cualquier ámbito en que ello fuese posible. Asi, podemos clecir que sacerdotal fue cuando perdonó a la adúltera y le devolvió la paz, curando se acerco a los leprosos para mostrarles que al menos Dios no los habia abandonado, cuando enseñó a orar llamando a Dios Padre, cuando dio de comer a los 
hambrientos y curó a los enfermos, cuando atacó a los opresores para que abrieran camino a Dios, etc. Sacerdotal fue para Jesús hacer presente a la gente cl amor de Dios, que la gente lo supiera y lo sintiera cercano y salvador; y sacerdotal fue también cuando inviló y exigió a los hombres a responder a Dios, y no hiciesen como el leproso curado desagradecido o el joven rico cobarde o, mucho inenos. como los poderosos que manipulaban a Dios en su propio interès.

Toda esta actividad configuró lo intirno de ia persona de Jesús, su existencia sacerdoral, podriamos decir. Para acercar a Dios a los hombres, él mismo se acercó a los hombres y a lo más débil de ellos. El mismo se acercó a Dios en la oración y en la obediencia, manteniéndose fiel hasta el final. Esta fidelidad a Dios y a los hombres fue lo que le desgastó, to que hizo de su vida una vida sacrificada; $y$, al linal, lo que le llevó al sacrificio de su propia vida, a ser él mismo victima.

Despućs de su resurrección, esa vida fue creída e interpretada teologicamente como verdaderamente mediadora y como salvación, pues en ella se acercó Dios en plenitud y para siempre, perdonando, sanando, salvando y plenificando a los hombres.

3.2. Las narraciones evangélicas admiten, por lo tanto, una lectura sacerdotal de Cristo; sistemáticamente son suficientes para establecer la realidad y la existencia saccrdolales, aun sin mencionar para nada la Carta a los Hebreros. El análisis de esta carta sigue siendo, sin embargo, importante por varios motivos. La carta es el único escrito del N.T. que analiza sistemáticamente el sacerdocio, y es por ello importante ver qué significa sacerdocio en la carta y qué metodologia usa para determinarlo. En cuanto al contenido, será importante conslatar si coincide y hasta qué punto con nuestra propia sistematización, aunque no se pueda esperar un paralelismo exacto ni se deban forzar los textos para conseguirlo. En cuanto a la metodologia, es importante constatar que la carta, aun conociendo ya los ministerios intraeclesiales, apela a la vida de Jesús para establecer la realidad sacerdotal. Es decir, la carta no afirma que Jesús sea sacerdote, como si ya se supiese con anterioridad a él lo que era el sacerdocio, sino lo contrario: sacerdote, ésc es Jesús. Esta obviedad sigue sin ser obvia -como lo muestra mucha argumentación para delerminar el sacerdocio ministerial, en donde se apela más eficazmente a la tradición intraeclesial que a la Carra a los Hebreos- y por ello es necesario recalcarla. Además la carta esclarece el sacerdocio positiva. pero lambién polémicamente, es decir, aclara afirmando lo que es y desenmascarando claramente lo que no es, con lo cual lo aclara mejor. Por último, la carta presenta el sacerdocio de Cristo ante la tenración de la comunidad de volver a una comprensión más cultual y religiosista de la fe cristiana. En efecto, los lectores de la carta eran cristianos cansados, atribulados y desalentados. La fe en Jesús les parecía demasiado fuerte y preferian por eso una religiosidad más Iradicional. Cansados por los sufrimientos que soportaban como cristianos $(10,32 \mathrm{ss} ; 12,3 \mathrm{ss})$ y desilusionados porque no habia acaecido la parusia $(3,14 ; 6,12 ; 10,36 s s)$ la antigua religlón, sobre todo su culto, ejerció un gran influjo sobre ellos. En este contexto, la carta no es una exposición pacífica del sacerdocio de Cristo, sino polémica contra la inna- 
la tenclencia a religiosizar la vida cristiana y así a deshisıorizala, y descmmascaradora de cualquier comprensión de lo sacerdotal que, sulil o burdancule. quiera orientarse según el modelo de las religiones.

Por todas estas razones, la carta sigue siendo de gran actualidad para decrminar la realiclad sacerdolal. A continuación vamos a analizar sistemática, no exegélicamente, algunos puntos nuy importantes de la carla que iluminen lo ya dicho: mas en concreto. la vigorosa sistematilación que la carta hace de la cxistencia sacerdotal y del sacrificio sacerdotal. Pero es importante lambién analizar en que consiste el servicio sacerdoral al nivel tco-lógico, pues éste es el que há guiado miestros analisis precedentes.

Lo más conocido de la carta es la declaración de nulidad e inclicacia del sacerdocio antiguo y la reinterpretación de la existencia sacerdotal, del culto y del sacrilicio. Hay que amalizar, sin embargo, al servicio de qué existe csa nueva existencia sacerdotal y cse nuevo sacrificio; es decir, la rclacionalidad constitutiva del sacerdote. En otras palabras, hay que analizar la relacionalidad constituliva de Cristo como sacerdole - lo cual en la carta como en lodo el N.T. es un supuesto básico- y explicitarla para no confundir servicio sacerdotal con existencia sacerdolal, por muy importante que ésta sea para aquél.

Que el sacerdocio sea servicio se dice claramente en la carta a partir del concepto formal de mediación. Que esa mediación se clecrmina de diverias formas a partir de lo que causa. Así, se dice, en general, que es "salvación eterna": (5.9), "conducir muchos hijos a la salvación" $(2,10)$, la "santificación" $(10,10)$, "poder entrar en el santuario, poder acceder a Dios" (10.19s). Más en concreto, se dice que Crisıo "realizó la purificación de nuestros pecados" (1,3; 10,11-14), "la purificación de nuestras conciencias de las obras de la muerte para que demos culto al Dios vivo" $(9,14)$, "Purificación en lo íntimo de ioda conciencia del mal" $(10,22)$.

La formalidad del servicio sacerdotal es, pues, clara: es el servicio de Cris10 a que Dios salve. Cabe preguntarse, sin embargo, si en la carta no se opera un reduccionismo de la salvación de Dios al perdón de los pecados, ignorando la amplitud de la salvación que antes hemos descrito como la finalidad del servicio sacerdotal. Para responder a esta pregunla hay qui lener en cuenta que en todo el N.T. el perdón de los pecados es esencial en la salvación, incluso un modo de nombrarla en totalidad, aunque tampoco la agote; y, más en concre10, que, dada la temálica y la polémica de la carta al hablar del nuevo sacerdocio, ciertamente tenia que quedar en claro que ese nuevo sacerdote perdona los pecados. Pero dicho esto, hay que investigar un poco más en qué consiste la salvación a cuyo servicio está el sacerdotc. No se debe intentar encontrar mecánicamente un paralelismo con lo antes dicho, pero tampoco se puede ignorar su afinidad.

En primer lugar, hay que recordar que la carta presenta la salvación también como alianza nueva y definitiva, superior a la del Sinai $(8,5)$ y predicha en Jer $31,31-34$, lexto citado en 8,6-13 y 10,16s. Alianza, aunque pueda ser comprendida cúlticamente y pueda ir acompañada de ritos cúlticos, es salvación en cuanto perdón de pecados, pero es lambién más que eso, como lo 
muestra el lexto de Jeremias. Qué sca la salvación que otorga esa alianza se puede colegiir de lo que la carla clice de la mucva forma de vida de los agraciados por la alianza. En cl pasaje siguiente a la mención de la nueva alianza se propone un sumario de la nueva existencia cristiana como "la plenitud de la fe," "la confesión lirme de la esperanza" y "la caridad y buenas obras" (10.19-25; clir. además. cap. 3,4 y 11 sobre la le; cap. 12 y 13 sobre la esperanza: 12,14 - 13,21 sobre la caridad). De la globalidad de la respuesla posibiliada por la nueva alianza se pucelc colegir en quc consisie la salvación que otorgo.

Pcro ademas de eso hay cuc preguntarse si en la carta está presente la salvacion globalisantc, expresada evangelicamente en los lérminos 'Padre' y "reino de Dios,' que ban sido clave para nucsura propia interpresación teológica de la realidad salcerclotal. Que cn la carta hay muchas afinidades con las narraciones evanecicals, es evidente en la descripción de importantes rasgos de Jesuis, su obediencia, lïlelidad, humanidad, elc. ¿Menciona de alguna forma lo equivalculc al Padre y reino de Dios? Sin forzar los textos ni buscar soluciones mecánicas, se pucde afirmar positivamente. G. Baena defiende que el servicio de Jesús al acercamiento del Padre y del reino de Dios tiene su equivalente en la carla en la misericordia del sumo sacerdote. Esta misericordia es descrila escuela y sistemáticamente, pero en momentos centrales. Del sumo sacerdote se dice que "se compadece de nuestras flaquezas" $(4,15)$ y por ello podemos tener confianza de "alcanzar misericordia" $(4,16)$, que "pudo sentir compasión" (5,2), que "es misericordioso" $(2,17)$. Esla misericordia de Jesús pudiera reducirse a condición previa para el ejercicio del sacerdocio; pero es algo más que eso. La acliva misericordia es lo que mueve a acercar la salvación y el ejercicio de la misericordia es la realización de la salvación.

Si la carta llama saccrdote a Cristo es porque ve en Jesús al hombre de la misericordia. En tos evangelios esta es descrita abundantemente y como algo central en Jesús. Jesús se compadece de todos aquellos que están en necesidad. "Vio mucha gente y se compadeció de ellos porque estaban como ovejas sin pastor" (Mc 6,34; Mt 9.36); al ver a la viuda de Naim con su hijo muerto "se compadecio de ella" (Lc 7,13); "vio mucha gente y compadecido de ellos curó a sus enfermos" (M! 14,14); se dice que sintió compasión por un leproso (cfr. Mc 1,41 ), por dos ciegos (Mi 20,34), por quienes no tenian que comer (cfr. Mc 8,2; Mt 15,32).

Esta compasión fluye de lo más hondo de las entrañas de Jesús y no es sólo un aspecto de su psicologia. La misericordia se convierte en criterio de acción, mediación de la voluntad de Dios, pues Jesús actúa según los dictados de esa compasión. Cuando Jesús quiere presentar al hombre que en verdad cumple la ley —el samaritano de la parábola - lo define como quien "tuvo compasión" (Lc 10,33). Más aún, Dios mismo es descrito como "movido por la misericordia" (Lc 15,20) cuando vio acercarse al hijo pródigo. Y Jesús exige de los hombres que "sean misericordiosos como el Padre es misericordioso" (Lc 6,36). 9

La carta llama sacerdote a Jesús por la misericordia que siente y praclica. Ese es el servicio mediador entre Dios y los hombres. Jesús "es expresamente 
entendido como la misericordia misma de Dios que llega en forma bien concreta a este mundo." 10

El ámbito de esa misericordia es globalizante y no regional; más aún, con tiempo de Jesús la misericordia es "lo que expresa de manera densa la Iotalidad de las grandes expectativas de la época mesiánica." La misericordia es entonces lo que relaciona sistemáticamnte a Jesús con el Padre y el reino de Dios. Jesús perdona pecados en el evangelio, rranquiliza a la adúltera, llorosa y humilde $(L c 7,50)$; pero por misericordia cura también enfermedades. $\Lambda 1$ menos en cuatro narraciones de milagros (M। 2,29-34 y par; $15.21-28$ y par; 17,14 29; Lc 17, 11-19) Jesús cura tras la petición: "Ien misericordia de mi." L:n la primera controversia de Marcos - aunque aqui sc cnfaliza la conıroversia y no tanto la misericordia de Jesús- Jesús cura a un paralitico y perdona sus pecados (Mc 2,1-12; M1 9,1-8; L.c 5,17-26). En esa miscricordia realiza lesius el acercamiento salvador de Dios. "La misericordia es el amor lípico de Dios que se inclina humildemente sobre los débiles para levantarlos." 12

En este contexto global de la misericordia hay que comprender el perdón de los pecadios como salvación. Cierlamente, sin perdón de los pecados no hay salvación, y parte muy importante de ésta es el perdón de los pecados. Pero visto desde la misma realidad salvadora de Dios, el perdón de los pecados es un momento de la salvación total. Dicho sistemáticamente y teniendo en cuenla la totalidad del N.T. podría describirse asi el proceso de salvación: Dios se ha compadecido de los hombres y se ha acercado en Crislo; vence al pecador desde dentro al acercársele con increible bondad; esa bondad la manifiesta visiblemente sanando también lo corpóreo del hombre. Y, a su vez, ese hombre que ha experimentado la misericordia de Dios es transformado él mismo para ejercitar misericordia hacia otros.

Esta es, creemos, una forma válida de interpretar la misericordia en la carta en relación con la esencia del servicio sacerdotal. Puede ser que se deba matizar exegéticamente; pero al nivel sistemático que nos ocupa podemos decir al menos que el ejercicio de la misericordia no es secundario para el servicio sacerdotal y explica mucho de él, aun en la carta. La realidad sacerdotal de Jesús puede ser descrita entonces de esta manera: "Jesús es la misericordia de Dios en persona que llega a este mundo, se acerca concretamente, fisicamente al hombre, lo toca en su temporalidad y en su carne, para que se entregue confiado e incondicional a esa misma acción de Dios y lo convierte en lo que Dios es, misericordia. El hombre perdonado es, a su vez., capaz. de misericordia."13

La carta presenta las caracteristicas [undamentales de la existencia sacerdotal al servicio del acercamiento salvador de Dios, es decir, como ha de ser y hacer el sacerdote en lo fundamental, cómo ha de relacionarse el sacerdole con Dios y con los hombres.

Por lo que toca a la relación con Dios, el sacerdote es elegido, llamado por Dios al sacerdocio $(5,5 s)$. El sacerdocio no es comunicado por la carne, sino por la llamada de Dios. "Es cosa sabida que nuestro Señor nació de Judá, y de esa tribu nunca habló Moisés tratando del sacerdocio"' $(7,13 \mathrm{ss})$. Esta conocida y repetida afirmación es de suma importancia, pues configura al sacerdote no 
sólo en su origcu en cuanto llamado, sino en su existencia. Esta existencia es ante todo tcologal: el sacerdocio se realiza en responsabilidad hacia Dios y, en úllimo término, hacia sólo Dios. De ahi que la carta describa la relación del sacerdole con Dios, no sólo como respuesia a la primera llamada, sino como obediencia $(5,8 ; 10,5-10)$, como disponibilidad permanente a la voluntad de Dios, novedosa c inınanipulable, a la cual no se le puede poner limites ni cauces preestablecidos, ni siquiera en cl ámbiro de lo sacerdotal. Por eso la carla afirma que Cristo fue sacerdote verdadero porque fue fiel a Dios $(2,17 ; 3,2)$, se inantuvo obedicnte a la volunlad de Dios, como lo muestran las narraciones evangélicas én los pasijes de la oración y de las tentaciones de Jesús.

Por lo quic loca a la relación con los hombres, el sacerdote debe ser cercano a los hombres, Irasiocando asi la categoria de separación, fundamental en el antiguo sacerdocio. Esa cercania es descrita sistemáticamenle de acuerdo a las narraciones evangélicas. De Cristo se dice programáticamente que fue en todo igual a los hombres menos en el pecado $(4,15)$; y para que no quede duda, se hace la inaudila alirmación de que Dios lo hizo "un poco inferior a los ángeles" $(2,9)$. Esta afirmación repite la unánime convicción del N.T. sobre la verdadera humanidad de Ćristo, pero en un contexto preciso y polérnico que ilumina la verdadera humanidad. Al parecer, en la religiosidad circundante existía un cierlo tipo de cristologia de los ángeles, fuertemente motivada por intereses soteriológicos. Los ángeles están cerca de Dios y por ello pueden operar la salvación; de ahi que existiese un culto a los ángeles "una mezcla seductora de falso misticismo y formalismo religioso."14 Ante este hecho la carta hace una doble alirmación: por un lado, la acción de Cristo es más poderosa que la de los ángeles, pues Cristo está más cerca de Dios, está a la diestra de Dios $(1,4)$; pero por otro lado, opera la salvación estando más cerca de los hombres, siendo "menor que los ángeles." Cristo no guia a la salvación desde arriba, como los ángeles, sino desde abajo, desde la plenitud de su humanidad. De esta forma, la carta rechaza la tentación de cualquier 'angelismo' sacerdotal, o en la forma cruda analizada o en sus sustitutivos a lo largo de la historia.

Esa verdaclera humanidad del sacerdole es afirmada como condición necesaria, pero no suficiente. La humanidad de Cristo es parte de la existencia sacerdolal en cuanto relacionada con los demás hombres y de forma bien precisa. Crislo no fue sólo hombre, sino hermano; es decir, no soblo semejante, sino cercano a los hombres, co-participante de la condición humana. Así se dice que "no se avergüenza de llamarles hermanos" $(2,11)$. Más aún, la carta muestra la parlicipación de Cristo en lo débil e imperfecto de la humanidad; se menciona su angustia $(5,7)$, su sultimiento $(2,10 ; 5,8)$. De esa forma, su cercania y semcjanza se convierten en solidaridad, pues fue probado en todo como ellos $(4,15)$ : porque él también sufrió puede ayudar a los que sufren $(2,18)$, porque ćl también cstuvo envuelio en flaqueza puede sentir compasión $(5,2)$. De esta forma sc recalca la parcialidad constitutiva de la existencia sacerdotal hacia y desde lo débil de este mundo.

Estas dos caracteristicas, fidelidad a Dios y solidaridad con los hermanos, son históricas en sus contenidos descriptibles, pero son también historicas en cuanto procesuales. La carta se recrea en afirmar que Cristo llegó a ser sacer- 
dote. Para ello afirma que lesís "tuvo que asemejarse en todo a sus hermanos" $(2,17)$, tuvo que pasar por "el aprendizaje" $(5,8)$. Cristo es presentado como sacerdote desde siempre y para siempre por sul elección $(5,6)$ : pero ese 'siempre' tiene una historia: Cristo fue perfeccionado $(2,10)$, Ilcgó a ser causa de salvación $(2,10)$. De ahi se concluye que la existencia sacerdotal no se da de una vez para siempre, ui se puede definir en abstracto. Se llega a ser sacerdote a través de un proceso, en lidelidad y solidaridad, que lience una culminacion en la entrega de la propia vida. Y ese "llegar a ser' realizado es lo que hace cle Cristo no sólo hermano, sino primogénito, posibilidad realizada de la sacerdo. ralidad de todo hombre. Por ello, el sumo sácerdore es deserilo lambién como precursor $(6,20)$ y pionero $(12,2)$. I a existencia sacerdolal se convierte entonccs en ejemplaridad.

La existencia sacerdotal descrita es contraria a la tradicional: acjuélla se realiza y se verifica en la historia, no en cl ámbito separado del culto. Esa diferencia la recalca la carta al mostrar la diferencia enirc los antiguos sacerdoles (separados, rigurosos con los hombres, peciadores, incapaces de entrat en la in. limidad con Dios) y Crislo, cercano, misericordioso, "santo, inocente, inconlaminado" $(7,27)$; entre el santuario y la ciudad donde Cristo mucre; cntre los ritos cultuales y carnales y la existencia de Cristo. Pcro la mayor diferencia y el mayor grado de historización del verdadero sacerdote ocurre en la determinación del sacrificio y la victima.

Para la lógica de la carta es evidente que no puede existir sacerdocio sin ofrenda sacrificial $(5,1 ; 8,3)$; el único problema está en la relación entre ambos. Si en el antiguo sacerdocio se podía distinguir entre sacerdote y victima, entre existencia sacerdotal personal y los ritos acompañantes del sacrificio, esa distinción ha quedado abolida. El ofrecimiento que hace Crislo es inseparable de su propia existencia: Cristo no entra en el santuario con sangre de machos cabríos, sino con su propia sangre $(9,12)$, no ofrece algo distinto de si mismo, sino que "se ofreció a si mismo" $(9,14.25)$. Los ritos que acompañan a su sacrificio son su propia vida y destino $(5,7-8 ; 9,15.26)$.

En la carta, por lo tanto, el sacrificio de Cristo es lo màs histórico de su sacerdocio y lo más sacerdolal de su vida histórica. Cabe preguntarse, sin embargo, por qué es eso así, qué relación existe entre el auto-sacrificio de Cristo y cl servicio sacerdolal teo-lógico; en olras palabras por qué y cómo esc sacrificio acerca a Dios. La carta no se plantea en directo esta pregunta porque según su conceptualización teológica el sacrificio es la esencia de la mediación. Pero más allá de ésta o de otra conceptualización teológica hay que preguniarse por la relación entre sacrificio y sacerdocio para cvilar, metodológicamente al thenos, adecuarlos, sin más.

Que el servicio al acercamiento de Dios es históricamente un servicio sacrificante es evidente; asi Pablo habla de los "duros trabajos del evangelio." Que ese servicio lleve o pueda llevar hasia el sacrificio de la propia vida, no se puede decidir a priori, pero ocurre. Los evangelios narran el hecho y aducen sus causas históricas; la carla constata y teologiza el hecho y apunta también, de hecho, a sus causas históricas: la fidelidad a Dios y la solidaridad con los 
hombres. Desde un punto de vista histórico no se puede excluir, sino más bien incluir, la posibilidad de que el sacerdorc lenga que entregar su vida, y de ahi el que la disponibilidad a ello sea parte de la existencia sacerdolal.

Pero eso lodavia no responde al más profundo por qué, a la relación conslitutiva entre sacerdocio y sacrificio, al por qué ese sacrificio es necesario para acercar a Dios a los hombres y por que es eficaz para acercarlo. A la primera pregunta no hay respuesta en último término -aunque el hecho se constate una y olra vez y el inismo N.T. argumentase de csa forma al comparar la muerte cle Cristo a la de un profeta. A firmar que ése es el designio de Dios no es más que elevar el escándalo a ministerio, pero no explicarlo. Negalivamence, sólo se puede decir que el servidor de Dios es vencido por los dioses de la muerte y que en el misıno Dios cxistc el momenı de impotencia ante esos dioses.

A la segunda pregunta - por qué cse sacrificio es eficaz- se puede responder con diversos esquemas soteriológicos; pero, en el fondo, tampoco ellos convencen, pucs no se ve como la destrucción en si misma se compagina con el Dios que quiere acercarsc salvadoramente. La única respuesta está en relacionar lo negativo del sacrilicio con lo posilivo del Dios que se acerca. Desde este punto de vista lo que dice la muerle de Cristo es que en Dios hay un gran amor - Trase absolutamente simple, pero insustiluible-, que ese amor es tan grande que, en lenguaje humano, enirega al Hijo (Rom 8,31; Jn 3,16), que la muerle de Cristo por amor hisı́rico a los hombres es expresión del amor a Dios. Que ese amor de Dios es además poderoso y eficaz. sólo aparecerá en la resurrección; pero lo que el sacrificio de Cristo recalca es la verdad de ese amor y la credibilidad de Dios. Al menos una cosa queda clara: es verdad que Dios se acercó a los hombres hasta el final y sin condiciones.

El sacrificio no es otra cosa que la consecuencia de una existencia sacerdolal verdaderamente proexisiencial, en favor de los hombres; mantenerse en el sacrificio no es otra cosa que decir de forma humana que en verdad se ama a los hombres y se busca su salvación. Según la fe cristiana es la totalidad del acontecimiento pascual lo que expresa la salvación y el acercamiento de Dios; la muerte/resurrección de Crislo es lo que genera la esperanza y la práctica de la caridacl, lo que expresa que Dios se ha acercado en definitividad y totalidad a los hombres, en el primogénito Jesús. Jesús ha sido resucitado porque fue salvador y la carla dice bellamente - de nuevo en una determinada conceptualidad - que sigue siendo salvador como resucitado, que sigue siendo "intercesor" $(7,25 ; 9,24)$. El sacrificio por si mismo no constituyc al intercesor, aunque lo acompañe; lo que lo constifuye como intercesor es el ser "en favor de los hombres." En último término, pues, es el amor lo que explica el sacrificio: el amor histórico a los hombres hasta el sacrificio que expresa el amor absoluto e incondicional de Dios. ${ }^{15}$

3.3. Podemos resumir ahora la diınensión cristo-lógica de lo sacerdotal, es decir, el servicio sacerdotal in actu. El sacerdocio de Cristo está al servicio del acercamiento de Dios; lo central de ese servicio es el cjercicio de la misericordia de Dios, quien se inclina hacia el débil, en lo que tiene de débil, pecador, angusliado, probado, etc. 
Ese servicio se realiza en una existencia teologal y en una existencia anıropológica, en obediencia liel a Dios y en solidaridad con los hermanos. Esa existencia sacerdotal es históricamente sacrificante por esa cloble caracteristica. conduce a dar de la propia vida y al sacrificio supremo de dar la vida. El que asi sea no se puede deducir a priori, pero una vez ocurrido se puede reinterprelar como la máxima expresión de fidelidad a Dios y a los hombres y, por olra parte, como lo que otorga credibilidad al Dios que se accrca.

\section{4. ¿Hay servicio sacerdolal en América Lalina?}

Al terminar estas reflexiones sobre el servicio sacerdotal queremos repelir cuál ha sido su intención. No hemos pretendido analizar los problemas concretos del sacerdocio ministerial en la actualidad ni el sentido técnico del sacerclocio común, que merecen un tratamiento explicilo. Lo único que hemos intenlado es exponer la sustancia, por asi decirlo, del servicio sacerdolal, que deberá estar presente en cualquier forma de su ejercicio eclesial. Hemos tratado de comprender el sacerdocio desde Dios y desde Cristo y no desde lo intraeclesial, por necesario y legitimo que esto sea. En ello nos hemos guiado por el método de la Carta de los Hebreos, la cual conoce los ministerios intraeclesiales (los anunciadores y testigos de la fe, 2,3s y 12,1; los dirigentes de la comunidad $13,7.17$ ), los alaba y los juzga muy importantes, pues "les han dicho la palabra de Dios" $(13,7)$ y "velan por sus almas" $(13,17)$, los hace también normativos, pues a esos ministros hay que obedecer e imitir en la fe $(13,7,17)$. Pero no los nombra sacerdotes - lo cual no es muy importante - ni intenta deducir de ellos la realidad sacerdotal - lo cual sí es imporiante recordarlo. Este trabajo tiene, pues, la obvia limitación de no haber considerado la dimensión eclesiológica del servicio sacerdotal, pero pretende haber superado una limilación más fundamental y una tentación más común: no comprender el servicio sacerdotal consecuentemente desde Dios y desde Cristo.

Hemos intentado también ofrecer un conceplo sistemático del servicio y existencia sacerdotales. De esta determinación sistemática pudiera decirse que es en exceso deductiva e, incluso, que prueba demasiado. Por lo que toca a la existencia sacerdotal no creemos que es así, pues la deducción a partir de Cristo es necesaria y la única manera de determinar la existencia sacerdotal en cuanto cristiana. Por lo que toca al servicio sacerdotal, pudiera objetarse que prueba demasiado porque lo que de è se ha dicho pudiera aplicarse lambien a la evangelización o a toda la misión de la Iglesia. Desde luego lo importante es determinar el servicio de la lglesia, sea que se le llame sacerdolal, evangelizador o simplemente eclesial. Pero sigue siendo importante la determinación de lo sacerdotal. En primer lugar, porque en la Iglesia se usa abundantemente el lenguaje de lo sacerdotal y algún contenido teo-lógico hay que poner a ese lenguaje. Si nuestra sistematización no pareciera adecuada, debiera buscarse otra, pero que relacionase el servicio sacerdotal con Dios y con la suficienteconcreción para dar cuenta de por qué se le llama sacerdolal. En segundo lugar tampoco se puede ignorar que lo sacerdotal es usado todavia hoy no infrecuentemente como uno de los modos de encubrir desviacionismos evangélicos, de 
alacar acciones novedosas y arriesgadas de la lglesia y de defenderse contra ellas. Coino en nombre de lo sacerdolal se suele a veces desprestigiar acciones auténticatnente cristianas, nos ha parecido importante describir a éstas como verdaderamente sacerdotales y asi de「enderlas. Por último, y positivamente, en el lenguaje de la Iradición y de las religiones lo sacerdotal se ha visto en relación con la salvación de Dios. Por eso hemos intentado reinterpretar el servicio sacerdotal desde esá salvación de Dios, aunque ésta deba estar tambièn presente al hablar de la evangelización, de la revelación, de la comunicación de Dios por la gracia, ecc. El análisis concreto que hemos hecho ha podido ayudar a concretar la especilicidad del servicio sacerdolal en su relación con la salvación de Dios, globalizante y por ello presente en el tratamiento de cualquier tema teológico.

Este trabajo ha pretendido esclarecer teoricamente la realidad sacerdotal, pero su origer: y linalidad no son puramente teóricos. En su origen está la observación de lo que ha hecho la Iglesia en América Latina y esto es lo que ha guiado cl análisis teórico a partir de un presupuesto básico: el servicio a la salvación es lo que hace a la Iglesia verdaderamente sacerdotal. Este presupuesto, conocido y aceptado teóricamente, ha dejado de ser lo meramente supuesto para convertirse en algo central debido a la realidad de la acción de la Iglesia. La finalidad del trabajo no ha sido otra que animar a la Iglesia a que sea más sacerdolal. Digamos para terminar unas palabras desde América Latina sobre rodo lo que hemos dicho de forma conceptual.

Anérica Latina ofrece un lugar óptimo para el servicio sacerdotal y su realidad histórica lo hace absolutamente necesario. Se trata, como en tiempo de Jesús, de pueblos enteros que necesitan urgentemente salvación y la esperan activamente. La miseria colectiva, la injusticia y la opresión, la aniquilación de culturas y pueblos indigenas, la represión, las torturas, los desaparecidos, los asesinados, las masacres, Ios refugiados, etc., muestran la urgencia de salvación. Esa realidad se ha convertido en poderoso clamor de los pueblos que lienen una gran esperanza: poder vivir y vivir con dignidad.

Esta esperanza de salvación la pueden describir en términos no religiosos, pero la expresan también religiosamente: la voluntad de Dios no es que el hombre muera, sino que viva, y ese Dios es capaz de darles vida. Además, en su búsqueda de salvación los pobres del continente se han vuelto también hacia la Iglesia -expresión, implicita quizás, pero eficaz., de que la salvación esperada sea lambién de Dios-, de modo que ellos han hecho una opción por la Iglesia antes de que la lglesia hiciese una opción por ellos.

Esla realidad y esta esperanza es lo que hace necesario y posible el servicio sacerdotal y el desafio fundamental al sacerdocio de la lglesia. El servicio sacerdotal deberá exlenderse a todos los ámbitos antes descritos, pero su gran ámbito, dentro del cual cobrarán relevancia los ámbitos concretos, es el ámbilo de la vida: "que tengan vida y vida en abundancia." Fuera o independientemente de ese ámbilo, vano seria el ejercicio parcial del sacerdocio, pues no se alimentaría de su más profunda savia teologal.

No lodos, por supuesto, han respondido a esa exigencia sacerdotal y entre 
quienes respondieron en un inicio puede haber retrocesos. Pero tampoco se puede dudar de que muchos - clesde cardenales y obispos hasta delegaclos de la paiabra y micmbros de commidades, como cristianos inclividuales y como grupos eclesiales, como comunidades, diócesis y hasia conferencias episcopales - han reacionado como el sumo sacerdote de la Carla a los Hebreos: con una gran miscricordia. Han sido lociacks por la miseria y la esperanza de vivir, y han dado cerdaclera primacia a esa miseria y a esa esperanza. Han cambiado sus ojos para ver esie mumclo con los ojos de Dios; han cambiaclo su corarón para semtir el dolor de este mundo como lo siente Dios. Esto ha hecho que sus pies -como los de quico anumcia la bucha nuevia - hayan re-

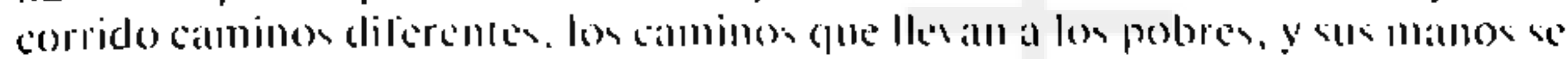
hayan puesto a Irabajar en su delemsa. Esıa gran miscricordia es la que esiá detrás de los movimientos de imsereion enlic los pobres, en el labajo por defender los derechos humanos. en las luchas por propiciar la justicia, en la cutrega por crear comunidades vivas. Dicho en palabras de Mons. Romero, la misericordia ha suregido de y propiciado lo lundamental: "Es preciso defender lo mínimo que cs el máximo don de Dios: la vida."

Esla es la actitud sacerdolal fundamental y, de hecho, asi la han interpretado los pobres. Esıos han caplado con la primariedad de quienes viven y sulren la realidad, anıcriormente a cualquier idcologización, que cn ese movimicnto celesial se la acercado la salvación y Dios con clla. Lo pongan o no cn palabra, y muchas veces lo hacen, caplan que el Dios del Exodo ha bajado una vez. más a liberarlos, que el Dios cle los cuarenta años del Sinaí les sigue acompañando, que el Dios cle los profetas ha salido de nuevo en su defensa, que el Dios de Jesús les ofrece de nucvo un reino, que el Dios de la cruz está con ellos hasta el final y que el Dios de la resurrección vuelve a producir el milagro de la esperanza y de la vida.

Que se hayan vuclıo a encontrar 'salvación' e 'Iglesia' es algo sumamente importante para los pobres y para la Iglesia; que asi se caple ambientalmente significa que la Iglesia se ha hecho verdaderamente sacerclotal y que la Iglesia ha revivido lo más fundamental de su le para poder ser sacerdotal: la le en un Dios que en verdad quierc salvar y la fe en la fuerza de Dios para salvar. Fsto que pudiera darse por supuesto por ser eleinental, no debiera serlo; pues una cosa es la repetición rutinaria y doctrinaria de la voluntad y capacidad salvilicas de Dios y olra muy distinta la convicción cle cue asi es y asi sc hace notar en la historia. Esa prolunda re en un Dios salvador es lo cuc ha movido a hacer presentc a Dios en la hisioria y lambién en cl corason del hombre. No hay reduccionisno - como tantas veces sc dice acusadoramentc-- en el servicio al acercamiento de Dios. Porque se cree realmente en un Dios salvador se ha lrabajado por instaurar su reino, pero lambién pala que ese reino sea de Dios: se ha trabajado por la líaternidad, pero Iambièn para que los hombres se encuentren con el Padre. En muchas comunidades, de pobres sobre todo, hay trabajo por la libcración, pero hay lambién un honiado y gozoso ponersc delante de Dios para convertirse, para abrirse a Dios, pero pedir que les llene del espiritu de las bienaventuranzas, para realizar cosas Ian importantes y difíciles como la reconciliación o el perdón, para irse haciendo como Jesús hijos del Padre celestial. 
El servicio sacerdotal quiere realmente llevar la plena salvación de Dios: pero su presupuesto - digámoslo una vez. más - es la convicción de que Dios es bueno para los hombres. Y un ejercicio asi de lo sacerdotal es lo que ha revalorizado la fe y la esperanza en Dios. Se ha revalorizado el 'reino' de Dios y el 'Dios' del reino, el 'amor' del Padre y el 'Padre' que ama a sus hijos. Esa revalorización es una verificación hisıórica de que ha liabido servicio sacerdotal. No cabe duda de que cuando la Iglesia ha realizado ese servicio ha crecido la te enire los creyentes, se ha robustecido la de los dubitanies y los no creyentes has tomado en serio al inenos lo que antes les icnia sin cuidado o consideraban como pura alienación. So ha revalorizado a "Dios" a travere del trabajo de acercár su 'salvación.'

Ese servicio sacerdotal ha generado una existencia sacerdotal que reproduce los rasgos que presenta la Carla a los Hebreos. Por un lado, la apertura a Dios, la búsqueda de su voluntad. No se pueden ignorar o reducir a simple función docirinal los ingentes esfuerzos por descubrir la actual voluntad de Dios, desde los grandes discernimientos de Medellin hasta las reuniones de las comunidades de base; la búsqueda de los signos de los tiempos en la miseria y en la esperanza, pero lambién cosas lan concretas como la organización popular de los campesinos, como lo reconocicron Mons. Romero y Mons. Rivera en una carta pastoral; las jornadas de reflexión, lantísimas rcuniones, la misma teología, etc. Desde un punto de vista sacerdotal, toso ello muestran la apertura a Dios y la fidelidad a la voluntad de Dios, buscada y discernida continuamente, la disponibilidad a nuevos mecanismos para encontrarla, como el diálogo entre jerarquia y bases, entre teólogos, cicntíficos sociales y agentes de pastoral, elc. Estas actividades, que aparecen en la publicidad, presuponen lambién la oración, personal o colectiva, gozosa o angusliada, ante Dios y se expresan también en la liturgia, en la celcbración de la palabra, elc. De esta forma la Iglesia se ha hecho sacerdole fiel.

Por otro lado, el acercamiento a los hombres. Después de mucho liempo, la Iglesia ha perdido el carácter de cierta exlerioridad con relación al continentte y se ha latinoamericanizado. Esto ha significado no sólo compartir la natllraleza o la cultura de los hombres y mujeres del continente. sino sobre todo lo que en ellos hay de débil y necesitado. La inserción entre los pobres, su solidaridad hacia ellos, su opción por ellos es la solidaridad sacerdotal de la Carta a los Hebreos, clecto y causa a la vez de la misericordia sacerdotal.

Esta existencia sacerdotal en el cjercicio del servicio sacerdotal ha producido innumerables mártices. Es una existencia sacerdolal consumada con la olrenda de la propia vida como la del sumo sacerdote. Existen por una parte millones de seres humanos que mueren lenta o violentamente, pueblos enteros crucificados, que mais se asemejan al siervo de Javbí que al sumo sacerdole, pero pueblos crucificados que -en la dificil afirmación de la fe- "salvarán a muchos." Pero además existen miles de cristianos que sufren la muerte como destino aceptado a causa de su servicio sacerdotal. Muchos han sido amenazados, capturados, desaparecidos, torturados y asesinados.

Este hecho nuevo y masivo en América I.atina es sumamente importante 
para verificar que ha habido servicio y existencia sacerdolales. A veces se suele presentar la casuistica sobre si son o no verdaderos mártires, como rambien se planteó sobre la muerte de Jesús, ajusticiado como blasfemo según unos y subversivo según otros. Si la casuistica es planteada de buena fe, entonces se llcga a la conclusión de que ha corrido abundante sangre sacerdotal. Y si lucse planteada de mala fe, entonces no sólo se haría una gravisima injusticia a tantos mártires, sino que metodológicamente - con la más poderosa melodologíu de la práctica que la puramente teórica- se estaria de nuevo en una pista equivocada para determinar la realidad sacerdotal y contraria a su escencia más profunda. Si se ignora tanta sangre derramada, si descle el linal salcedolal del proceso no se aprende a reconocer lo que de sacerdotal hubo en el servicio, si en la entrega generosa de la vida no se descubre la gran misericorclia sacerclotal y la fidelidad a Dios, si no se hace de lodo eso algo iluminador y central en la determinación sacerdotal, enlonces no vemos como se pueda llegar a comprender lo que es sacerdotal; pero entonces rampoco se podria apelar a li Carta a los Hebreos para su comprensión. Si cuando los cristianos se parecen más a .Icsús no se descubre ese parecido, es que entonces - a pesar de muchas declaraciones en contrario - la esencia de lo sacerdolal ya se ha establecido con antcrioridad lógica al análisis del sacerdocio concrelo de Cristo.

¿Puede resumirse en una palabra la realidad sacerdolal? El Vaticano II recuerda que es procurar la gloria de Dios. Por coincidencia o por lortuna, tam bién en América Latina se ha usado ese lenguaje. Mons. Romero citó el conocido texto de Ireneo: Gloria Dei vivens homo; vila aulem hominis visio Dei. La primera parte la reinterpretó vigorosamente: la gloria de Dios es el pobre que llega a vivir. La segunda parte la parafraseó en la rcalidad, aun sin aludir explícitamente a ella, cuando afirmó que "ningún hombre se conoce micnlras no se haya encontrado con Dios." Toda su misión, como la de lantos otros, consistió en acercar a Dios, acercando vida a los pobres y en hácer que todos, especialmente los pobres, se acercaran a Dios para vivir en plenilud.

Eso es lo que hizo que Ioda una Iglesia fuese sacerdotal c incluso guc se renóvase lo sacerdotal intraeclesial desde lo sacerdotal apostólico. Pero el origen de todo estuvo en la gran misericordia que sintio por los pobres de este mundo, en la lidelidad a Dios para encontrar salvación pero esos pobres y ell ol valciamiento interno y crucificante de sí mismo para poder ser mediador y sacerdote. Muchos otrus han sido y son como Mons. Romero, y por ello ha habiclo y hay realidad sacerdotal en América I.alina. I.o que se siguc necesitando or una lglesia que sea no menos, sino más sacerdotal. 


\section{NOTAS}

I. Por lo que loca al N.T. la novedad de la salvación era tal que en un primer momento no lıabia sacerdotes en las comunidades; pero lo importante es comprender por qué: "Si es que es cierto que los primeros cristianos no tuvieron sacerdotts, entonces es que su manera de enIender a Dios y de praclicar la re y la relación con Dios Iuvieron que ser cosas profundamente revolucionarias ел aquel tiempo y en aquella socicdad." J.M. Castillo, "Sacerdocio," en Conceplas fiendamentales de pastoral. Madrid, 1983, 888. Por to que toca a Lutero, su rechazo del orden sacerdolal como sacramenıo y su revalorización del sacerdocio común se debe no sólo a que, según su melodologia, no encuentra en la Escrilura una fundamentación para el ordell como sacramento, sino más de fondo, a que los sacerdotes no mediaban salvacion. sino opresiom; no fomentatan la liberlidy fraternidad cristiana, sino la esclavitud. Con crio se quicere indicar yue el cambio profundo de lo sacerdoral ocurre cuando cambia profundamente la comprensión de la salvación.

2. Por lo que loca it Mons. Romero, no cabe duda de su aprecio y revalorización del sacerdocio ministerial, cir. La irez de los sin boz (San Salvador, 1980, 329-334, 342-344) y, mís novedosamentc, de su revalorización in ac/ll del sacerdocio comun. Este fue polenciado a los diversos niveles de parlicipación pastoral, litúrgica, adminisırativa, al decisivo nivel de la práctica de la salvación. Pero la raiz. Je lodo ello csiaba en la aceplación de que la misma fe, la caplación de la manilestación de Dios en el presente, la realizaba la lglesia en su totalidad (cfr. $L G$ 12). De ahi qui Mons. Romero hiciese participar a lodos en la Iglesia, en la aclaración de los signos de los tiempos y en cómo responder a ellos. Antes de escribir su cuarta carta pastoral y de presenlar su informe a Puebla consultó al pueblo de Dios con seriedad. De ese modo, no reservó para la jerarquia aquello que en último término suele diferenciar su sacerdocio del de los fieles: la captación de la manilestación y la voluntad de Dios.

3. Alrededor del Vaticano II la teologia inientó superar una teologia del sacerdocio desde el cul10 y la separación del mundo en favor de una teologia desde la palabra y la encarnación, siguiendo sobre codo una melodologia crisıológica para determinar la realidad sacerdotal. Veánse los articulos clásicos de K. Rahner en Escrilos de Teologia III y IV, Madrid, 196I, 1964; J. Ralzinger, "Zur Frage nach dem Sinn des priesterlichen Dienstes," Geis und Leben 1968, 4I, 347-336: W. Kasper, "Die Funktion des Priesters in der Kirche," Geist und Leben 1969, 42, 102-106; H. Urs von Balthasar, "Der Priester im Neuen Testament. Eine Erganzung," Geist und Leben. (1970). 43, 39-45; el clásico irabajo exegético de H. Schlier. "Grundelemente des priesterlichen Amies in Neuen Testament," Theologie und Philosophie. $1969,44,16 / .180$.

4. F. Wulf en su comentario al decreto conciliar sobre el servicio y la vida de los presbiteros (PO). Lexikon für Theologie und Kirche, Das Zweile Varikanische Konzil III (Freiburg, 1968, 142-169), reconoce las novedades positivas mencionadas, pero recalca que el concilio no fundamento consecuentemente el sacerdocio ministerial en el sacerdocio más abarcador de todo el pueblo de Dios (147, 148 y 152).

5. No se puede negar que la lglesia muesira en general mucha mayor reserva y pusilanimidad al Isatar problemas teológicos concretos que tienen que ver con ella misma y, sobre todo, con sus aspectos instilucionales (sacerdocio ministerial, minisıro de los sacramentos, posible ordenacion de mujeres, etc.) que al tratar los grandes temas teológicos, como Cristo, Dios, la cvangelización. etc. Está ayui actuando consciente o inconscientemente un mecanismo de autoderensa de lo imstilucional y jerárquico.

6. I.a renovación sacerdotal en América Latina se ha realizado más a partir de una práctica comprometida con el mundo de misetia y esperanza que a partir de textos doctrinales. El espiritu de Medellin ha estado presente en esa nueva práctica, pero no tanto el documento sobre los sacerdoles el cual reproduce en lo sustancial lo que dice el Valicano Il con algunas suaves concreciones sobre la necesidad de participar en "el proceso de desarrollo del continente" (n. (8) y la llamada a la pobreza evangélica (n.27). Lo mismo cabe decir de Puebla, aunque reconoce más explicitamente la necesidad de que el sacerdote trabaje por una liberación integral (n.696). alaba el mayor acercamiento al pueblo y la mayor pobreza (n.666), incorpora en la existencia sacerdolal la disponibilidad al sufrimiento y el martirio (n. 668). Al nivel teológico no creemos que se haya abordado en direcio y sistemáticamente el sacerdocio, pero no cabe duda de que la teologia de la liberación ha replanteado su realidad, aun sin sombrarlo, y ha dado pistas para responder a su problemática. 
7. J.M. Castillo. op. cii., 888.

8. "El Sacerdocio de Crislo," Diakonia. 1983, 26, 123.134.

9. A. Nolan, Jesus before Christianiry (New York, 1976). Hace de csa misericor diat de levis al:au ceniral para comprender un misión y lo synccilion de ella.

10. G. Bacna, op. cil., 130.

11. Ibid.

12. Ibid.

13. Mid. I.13.

14. A. Vanhoye, Le Christ est motre mietre. Romm, 1969. 19.

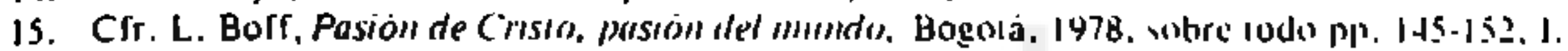

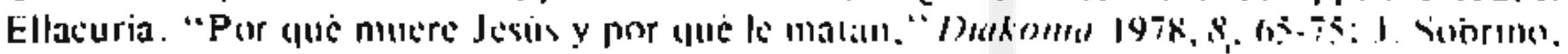

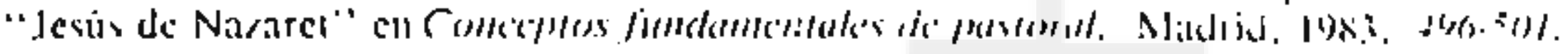

